\title{
Closing the Regulatory Gap for Synthetic Nicotine
}

\author{
59 B.C. L. REV. \\ (forthcoming 2018) \\ Patricia J. Zettler \\ Natalie Hemmerich \\ Micah L. Berman* \\ October 2017 Draft \\ Please direct any comments to: pzettler@gsu.edu
}

\begin{abstract}
In July 2017 the U.S. Food and Drug Administration (FDA) announced a new "comprehensive plan for tobacco and nicotine regulation." This plan is focused on making cigarettes less addictive while facilitating the development of alternative nicotine-containing products that are far less harmful. This approach holds promise, and the public health stakes could not be higher-smoking is the leading cause of preventable death in the United States, causing roughly 480,000 deaths per year.

But a new product is emerging that could upset the FDA's plans for a well-balanced regulatory scheme: synthetic nicotine. These products currently fall into a regulatory gap because they fall outside the Federal Food, Drug, and Cosmetic Act's (FDCA) definition of a tobacco product. If this gap remains in place, it is likely that more companies will exploit it in order to evade regulation, undoing the potential benefits of the FDA's plan for tobacco and nicotine regulation.

This Article argues that the FDA can, and should, address this problem by regulating synthetic nicotine products as drugs. After reviewing the science of nicotine addiction and the FDA's past and present regulatory schemes for nicotine, it explains how the FDA could establish that synthetic nicotine satisfies the FDCA's definition of a drug. It concludes with a discussion of the policy benefits of categorizing synthetic nicotine as a drug.
\end{abstract}

\footnotetext{
${ }^{*}$ Patricia J. Zettler, J.D., is an associate professor at Georgia State University College of Law. Natalie Hemmerich, J.D., M.P.H., is a postdoctoral fellow at Ohio State University's Center of Excellence in Regulatory Tobacco Science. Micah L. Berman, J.D., is an associate professor Ohio State University's Moritz College of Law and College of Public Health. The Ohio State University's Center of Excellence in Regulatory Tobacco Science, where Ms. Hemmerich works, is funded through grant number P50CA180908 from the National Cancer Institute and the FDA Center for Tobacco Products (CTP). The content of this Article is solely the responsibility of the authors and does not necessarily represent the official views of the National Institutes of Health or the Food and Drug Administration.
}

For helpful discussion, comments, and questions, the authors would like to thank the participants in Stanford Law School's 2017 Law and the Biosciences Conference and the American Society of Law, Medicine, and Ethics's 2017 Health Law Professors Conference. [Additional Acknowledgements] 


\section{Table of Contents}

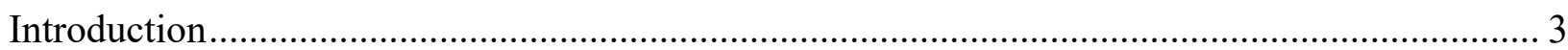

I. How We Got Here: Understanding Nicotine and the FDA's Nicotine-Related Jurisdiction ...... 5

A. Nicotine's Effects on the Body ................................................................................... 5

B. The FDA's History of Using its Drug-Related Authority to Regulate Tobacco and Nicotine

1. The 1996 Rule: The FDA's First Attempt to Regulate Tobacco Products...................... 9

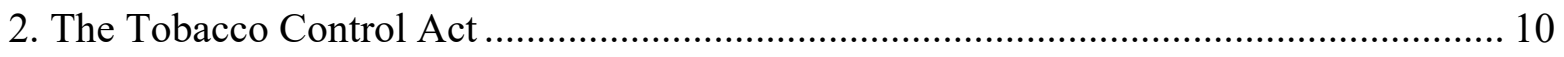

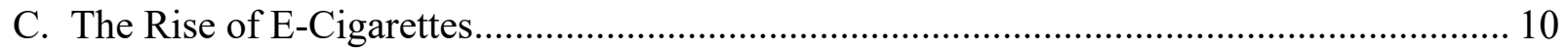

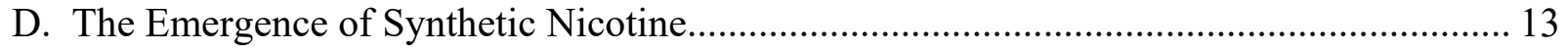

II. The Legal Case for Regulating Synthetic Nicotine as a Drug ......................................... 14

A. The Flexibility to Regulate Synthetic Nicotine as Drug ............................................... 15

B. The Intended Use of Synthetic Nicotine.................................................................... 17

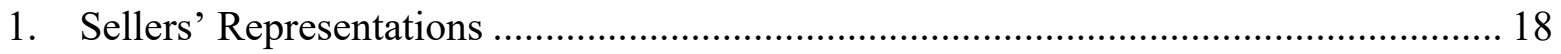

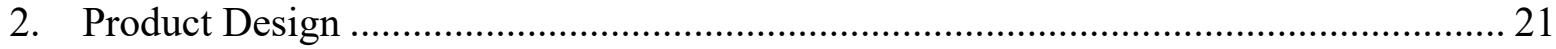

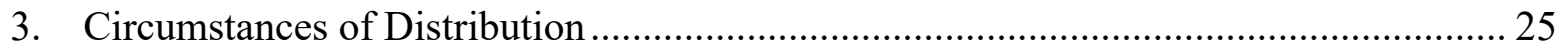

III. The Policy Case for Regulating Synthetic Nicotine as a Drug ........................................ 27

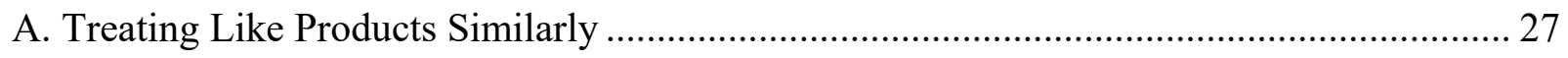

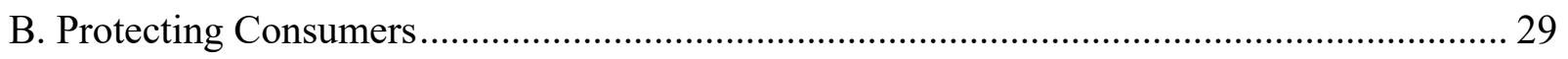

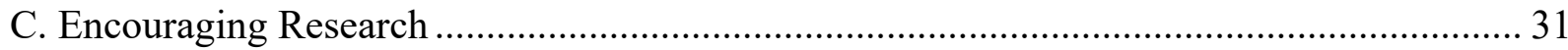

D. Promoting Innovation and Minimizing Burdens ........................................................... 33

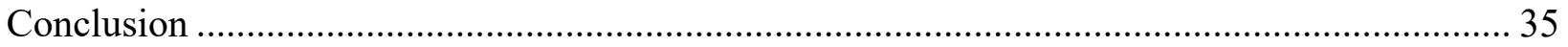




\section{INTRODUCTION}

In July, U.S. Food and Drug Administration (FDA) Commissioner Scott Gottlieb announced a new "comprehensive plan for tobacco and nicotine regulation," intended to "place nicotine, and the issue of addiction, at the center of the agency's tobacco regulation efforts." The FDA's plan recognizes that although nicotine use carries some risks, it is "not directly responsible for the cancer, lung disease, and heart disease that kill hundreds of thousands of Americans each year." ${ }^{2}$ Nicotine makes tobacco products addictive, but it is their other components and properties - not the nicotine - that make them deadly. Cigarettes are particularly lethal; they kill more than half of their long-term users. But because cigarettes are also astonishingly effective at delivering nicotine quickly to the brain, they are also by far the most popular tobacco product.

Based on these insights, the FDA is proposing a "nicotine-focused framework for public health" that seeks to make the most deadly forms of tobacco use (i.e., cigarettes and other combustible products) less addictive while simultaneously encouraging the development of less harmful ways to deliver nicotine to those already addicted. ${ }^{3}$ These are laudable aims, and the public health stakes could not be higher. Smoking is currently the leading cause of preventable death in the United States, causing roughly 480,000 deaths per year-appreciably more than other high-profile public health problems, such as drug misuse and overdose. ${ }^{4}$ If cigarettes were gradually phased out and replaced by noncombustible forms of nicotine use, it is quite possible that "the great majority of tobacco-caused diseases and deaths would disappear."

In pursuing these goals, the FDA is aided by the powerful regulatory tools granted to it by the 2009 Family Smoking Prevention and Tobacco Control Act (TCA). ${ }^{6}$ Although the health harms of tobacco use have been well established for decades, it was not until the TCA that Congress gave the FDA broad authority to regulate the manufacturing, sale, and marketing of tobacco products. In 2016, the FDA finalized a rule (referred to as the "deeming rule") that extended its regulatory authority to all products meeting the TCA's statutory definition of a tobacco product, notably including electronic cigarettes (or e-cigarettes). Between the TCA and

\footnotetext{
${ }^{1}$ Press Release, Food and Drug Administration, FDA Announces Comprehensive Regulatory Plan to Shift Trajectory of Tobacco-Related Disease, Death (Jul. 28, 2017) available at https:/www.fda.gov/NewsEvents/Newsroom/PressAnnouncements/ucm568923.htm [hereinafter FDA Nicotine Announcement].

${ }^{2}$ Scott Gottlieb, Commissioner, U.S. Food \& Drug Admin., Protecting American Families: Comprehensive Approach to Nicotine and Tobacco (prepared remarks), July 28, 2017, https:/www.fda.gov/NewsEvents/Speeches/ucm569024.htm (emphasis added).

${ }^{3}$ Scott Gottlieb \& Mitchell Zeller, A Nicotine-Focused Framework for Public Health, New ENG. J. MED. (2017) (online ahead of print), http://www.nejm.org/doi/full/10.1056/NEJMp1707409?query=featured_home.

${ }^{4}$ See, e.g., Ctrs. for Disease Control and Prevention Smoking \& Tobacco Use, https://www.cdc.gov/tobacco/data_statistics/fact_sheets/fast_facts/index.htm.

${ }^{5}$ Richard A. Daynard, Doing the Unthinkable (and Saving Millions of Lives), 18 TOBACCo ConTrol 2, 2-3 (2009).

${ }^{6}$ See generally Family Smoking Prevention and Tobacco Control Act, Pub. L. No. 111-31, 123 Stat. 1776 (2009).
} 
the later deeming rule, the FDA now has the authority to regulate all products "made or derived from tobacco [and] intended for human consumption." "7

However, if the FDA is seeking to "comprehensively" regulate nicotine, there is still a notable regulatory gap: synthetic nicotine. ${ }^{8}$ In just the past few years, synthetic nicotinewhich is synthesized through chemical reactions in a lab-has entered the marketplace, primarily as an ingredient for use in e-cigarette liquids. The sellers of synthetic nicotine recently celebrated the FDA's acknowledgement that it cannot regulate such products under the TCA, because they are not "made or derived from tobacco." This leaves a regulatory gap that may become much more significant as the FDA begins to regulate e-cigarettes and as the price of synthetic nicotine continues to fall.

Sellers of synthetic nicotine, though, are perhaps celebrating their escape from regulatory oversight prematurely. Although the FDA is unable to regulate synthetic nicotine as a tobacco product under the TCA, the agency could potentially regulate it as a drug under the Federal Food, Drug, and Cosmetic Act (FDCA). To establish that synthetic nicotine is a drug, the FDA would have to show that synthetic nicotine is "intended for use in the diagnosis, cure, mitigation, treatment, or prevention of disease" or "intended to affect the structure or any function of the body." "The FDA's authority to regulate synthetic nicotine as a drug, thus hinges on the meaning of "intended use" and the kinds of evidence that the DFA may use to demonstrate a product's intended use - issues that have long been controversial.

In this article, we argue that the FDA can and should regulate synthetic nicotine as a drug under the FDCA. Diving into the case law on "intended use," we demonstrate that although the case law on some key points remains unsettled, the FDA can make a convincing legal case that synthetic nicotine is best characterized as a drug under the FDCA. Then, as a policy matter, we explore why the FDA should regulate synthetic nicotine as a drug in order to protect consumers, encourage research, and treat like products similarly.

This article proceeds in three parts. Section I provides background on the biological effects of nicotine, the FDA's history of tobacco and nicotine regulation, and the emergence of synthetic nicotine. Section II discusses the FDA's legal authority to regulate synthetic nicotine as a drug, and Section III lays out the public policy and public health reasons that the FDA should do so.

\footnotetext{
${ }^{7} I d$. at $\S 101(\mathrm{a})(1)$; The definition also includes components, parts, and accessories of tobacco products and excludes products that are classified as drugs or devices under the Food, Drug, and Cosmetic Act, even if those products are made or derived from tobacco. Id. at (a)(2).

${ }^{8}$ To the best of authors' knowledge, the only nicotine not made or derived from tobacco that is currently being sold on the market is synthetic nicotine. However, there are other potential non-tobacco sources nicotine. For example, tomatoes, eggplants, and other vegetables also contain nicotine in small quantities. While it may not be economically feasible to derive nicotine from these sources at this time, if the FDA decides to regulate synthetic nicotine, it should frame its regulation to cover all non-tobacco sources of nicotine, so as to avoid future attempts to evade regulation. For the purposes of this paper, synthetic nicotine is specifically addressed, but all arguments and policy implications apply with equal relevance to any other non-tobacco sources of nicotine.

${ }^{9}$ Food, Drug and Cosmetic Act, 21 U.S.C. 321(g)(1)(c) (2001).
} 


\section{How We Got HeRe: Understanding Nicotine AND tHe FDA's Nicotine-Related JURISDICTION}

In 1994, the seven major tobacco company CEOs all testified before a congressional hearing that they believed nicotine was not addictive. ${ }^{10}$ This was, of course, untrue- " $[t]$ he companies themselves had carefully documented the effects of nicotine on the brain" 11 -but the companies feared that acknowledging nicotine's addictive effects could subject them to FDA regulation.

More than twenty years after this historic hearing, the landscape has shifted dramatically. The addictiveness of nicotine is no longer in dispute and the FDA now has regulatory oversight over tobacco products. But the effects of nicotine are still widely misunderstood, ${ }^{12}$ and the rise of e-cigarettes, and, more recently, the emergence of synthetic nicotine, continues to present the FDA with challenging legal and regulatory decisions.

This section presents the scientific and legal background necessary to explore whether and how the FDA should regulate synthetic nicotine. It examines how nicotine affects the human body how FDA has regulated (or tried to regulate) tobacco and nicotine, how e-cigarettes fit into the FDA's regulatory scheme, and, finally, how the synthetic nicotine threatens to upset the FDA's effort to comprehensively regulate nicotine.

\section{A. Nicotine's Effects on the Body}

Since the 1950s, the major tobacco companies have been aware that nicotine is an addictive substance. ${ }^{13}$ For instance, in 1963, an internal Brown \& Williams report recognized that "nicotine is addictive" and the company was therefore "in the business of selling nicotine, an addictive drug." " Likewise, a 1969 Philip Morris report recognized that "the primary motivation for smoking is to obtain the pharmacological effect of nicotine." 15 But motivated in part by fear of FDA regulation, the industry worked to conceal evidence of nicotine's addictiveness for decades. ${ }^{16}$

${ }^{10}$ William B. Schultz, The FDA's Decision to Regulate Tobacco Products, 18 PACE L. REV. 27, 33 (1997).

${ }^{11}$ Id.

${ }^{12}$ Jennifer C. Morgan, M. Justin Byron, Sabeeh A. Baig, Irina Stepanov, Noel T. Brewer, How People Think about the Chemicals in Cigarette Smoke: A Systematic Review, 40 J. BEHAVIORAL MED. 553, 557 (2017).

${ }^{13}$ United States v. Philip Morris, 449 F.Supp.2d 1, 515 (D.D.C. 2006).

${ }^{14}$ Report from Addison Yeaman, Brown \& Williamson, Implications of Batelle Hippo I \& II and the Griffith Filter (Jul. 17, 1963) (available at https://www.industrydocumentslibrary.ucsf.edu/tobacco/docs/hrwh0097).

${ }^{15}$ Report from Philip Morris, Why One Smokes (Feb. 1969) (available at https://www.industrydocumentslibrary.ucsf.edu/tobacco/docs/tnjm0129).

16449 F.Supp.2d at 653. ("The Defendants [tobacco industry leaders] have repeatedly made vigorous and impassioned public denials - before Congressional committees, in advertisements in the national print media, and on television - that neither smoking nor nicotine is addictive, and that they do not manipulate, alter, or control the amount of nicotine contained in the cigarettes they manufacture."). 
Despite the industry's past denials, it is now beyond dispute that "[n]icotine is the drug in tobacco that causes addiction." 17 The physiological mechanisms are complex, but in short, exposure to nicotine actives the nicotine-specific receptors in the brain, and this activation in turn increases levels of dopamine and other neurotransmitters. Dopamine provides a pleasurable sensation, and the reinforcing effects of dopamine create and sustain addiction. Importantly, the brain adapts to repeated nicotine use, and increased tolerance for nicotine is reflected in physiological changes; chronic nicotine exposure alters the brain's structure by increasing the number of nicotine-specific receptors. ${ }^{18}$

Nicotine addiction is characterized by the user's need to continue dosing, both to maintain the reinforcing effects of nicotine and to reduce the incidence of withdrawal symptoms. ${ }^{19}$ The reinforcing effects of nicotine on the brain (and other systems) include increased "relaxation, reduced stress, enhanced vigilance, improved cognitive function, mood modulation, and lower body weight." ${ }^{20}$ Conversely, when withdrawing from nicotine, users experience "nervousness, restlessness, irritability, and anxiety." 21 For regular smokers, the effects of nicotine can wear off quickly; within 30 minutes of smoking, they may already start to feel symptoms of both physical and psychological withdrawal. ${ }^{22}$

In addition to causing addiction and relieving withdrawal symptoms, nicotine exposure apart from the risks associated with other components in tobacco - is particularly harmful for developing brains. For a fetus (exposed through maternal nicotine use), nicotine exposure can cause cellular damage to the brain that is associated with behavioral challenges later in life, including learning disabilities and hyperactivity disorder. ${ }^{23}$ Nicotine also restricts the flow of nutrients and oxygen to the fetal tissues, which is linked to congenital deformities and impaired cardiac development. ${ }^{24}$ For these reasons and others, nicotine is classified as a developmental toxicant by the California Environmental Protection Agency. ${ }^{25}$

Likewise, adolescents - who also have still-developing brains - are also particularly vulnerable to nicotine exposure. ${ }^{26}$ Because nicotine exposure at this age also induces structural

${ }^{17}$ OfFICE ON SMOKING AND HeAlth, U.S. DepartMENT OF HEALTH AND HuMAN SERVICES, The HeAlth CONSEQUENCES OF SMOKING: NiCOTINE ADDiCTION: A REPORT OF THE SURGEON GENERAL 9 (1988).

${ }^{18}$ Id. at $598-99$

${ }^{19}$ Id. at 601. See also OFFICE ON SMOKING AND HEALTH, U.S. DEPARTMENT OF HEALTH AND HUMAN

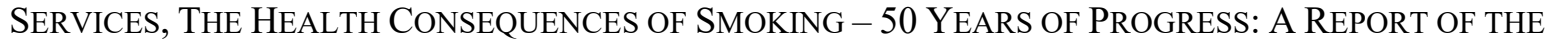
SURGEON GENERAL, 112 (2014) [hereinafter 2014 Surgeon General's Report].

${ }^{20}$ Neal L. Benowitz, Pharmacology of Nicotine: Addiction and Therapeutics, 356 ANN. REV. OF PHARMACOLOGY \& TOXICOLOGY 597, 601 (1996).

${ }^{21} I d$.

${ }^{22} \mathrm{Id}$.

${ }^{23} 2014$ Surgeon General's Report, supra note 19, at 121 (citing Theodore A. Slotkin, Fetal Nicotine or Cocaine Exposure: Which One Is Worse? 285 J. OF PHARMACOLOGY \& EXPERIMENTAL THERAPEUTICS $931(1998))$.

${ }^{24}$ See Donna S. Lambers \& Kenneth E. Clark, The Maternal and Fetal Physiologic Effects of Nicotine, 20 SEMINARS IN PERINATOLOGY 115 (1996).

${ }^{25} 2014$ Surgeon General's Report, supra note 19, at 471.

${ }^{26}$ Neuroscience research over the past few decades have shown, contrary to earlier assumptions that brain development continues into one's twenties. See, e.g., ElizABETH S. SCOTT \& LAURENCE STEINBERG, RETHINKING JUVENILE JUSTICE 44 (2010). ("Scientists have found clear evidence that the brain continues 
changes in the brain, those who begin tobacco use as adolescents are more likely to smoke into adulthood, have more difficulty quitting, and experience deeper levels of addiction. ${ }^{27}$ Other consequences of early nicotine exposure include changes to the developing limbic system (the emotional core of the brain), which increases the likelihood of developing mood disorders, attention and cognition disorders, and drug-seeking behaviors. ${ }^{28}$

While the effects outlined above raise public health concerns, nicotine itself - separate and apart from tobacco use - also may hold promise as a treatment for certain medical conditions. For instance, there is some preliminary evidence that nicotine could be used to treat the symptoms of Alzheimer's disease, Parkinson's disease, Schizophrenia, and other illnesses. ${ }^{29}$

In short, although nicotine is not the lethal component of tobacco products, it is well known that nicotine use causes addiction and well as other negative public health consequences. ${ }^{30}$ For purposes of FDA regulation, it is notable that it does so by inducing permanent physiological changes in the brain. Nicotine, isolated from tobacco, may also hold some public health promise. Of course, if a nicotine-containing product were marketed as a treatment for a disease or its symptoms, there is no question that it would appropriately considered a drug by the FDA.

\section{B. The FDA's History of Using its Drug-Related Authority to Regulate Tobacco and Nicotine}

The FDA oversees drugs throughout their lifecycle, from the start of research through their use in clinical care. A critical component of the FDA's regulation of drugs is the agency's gatekeeping function. A new drug cannot be marketed in the United States unless the FDA determines it is safe and effective for its proposed use. ${ }^{31}$

What constitutes a "drug" subject to the FDA's authority? Under the FDCA, a drug is defined as an "article" that is "intended for use in the diagnosis, cure, mitigation, treatment, or

to mature through adolescence and into the early twenties, with large-scale structural change taking place during this period....").

${ }^{27}$ OfFICE ON SMOKIng AND HEALth, U.S. DePartment OF HeAlth AND Human SERVICES, ECigarette Use Among Youth and Young Adults: A Report of the SurgeOn General, 105 (2016) [hereinafter 2016 Surgeon General's Report].

${ }^{28}$ See e.g. Eric R. Kandel \& Denise B. Kandel, A Molecular Basis for Nicotine as a Gateway Drug. 371 New Eng. J. Med. 932 (2014). Menglu Yuan, Sarah J. Cross, Sandra E. Loughlin, \& Frances M. Leslie, Nicotine and the Adolescent Brain, 593 J. PHYSIOLOGY 3397 (2015).

${ }^{29}$ E-Cigarette Use AmONG Youth AND Young Adults at 123. See also Benowitz at 607.

${ }^{30}$ In addition to the health consequences discussed in the section, nicotine "can have adverse effects during pregnancy and may contribute to cardiovascular diseases." In addition, "Although nicotine itself is not a carcinogen, it may function as a "[tumor] promoter." WHO FRAMEWORK CONVENTION ON TOBACCO CONTROL, ELECTRONIC NICOTINE DELIVERY SYSTEMS 3 (2014) available at http://apps.who.int/gb/fctc/PDF/cop6/FCTC_COP6_10-en.pdf.

${ }^{31} 21$ U.S.C. $\S \S 331(\mathrm{~d}) ; 355(\mathrm{a})$, (d). "New drugs," as defined by the FDCA, are those drugs that are not generally recognized as safe and effective, or have not been marketed for a material time and to a material extent. $21 \S$ U.S.C. 321(p). The overwhelming majority of prescription drugs, and over-the-counter drugs introduced into the market after 1972, are new drugs. See, e.g., U.S. Food \& Drug Admin., Marketed Unapproved Drugs - Compliance Policy Guide 12 (2011), https://www.fda.gov/downloads/Drugs/GuidanceComplianceRegulatoryInformation/Guidances/UCM070 290.pdf. 
prevention of disease" or "intended to affect the structure or any function of the body." 32 The "intended use" of a product - determined by the "objective intent of the persons legally responsible for the labeling" 33 — is the key to determining whether on not a product is a drug within the FDA's jurisdiction. ${ }^{34}$ Although the FDA has applied commonsense limits to its interpretation of what falls within the drug definition, ${ }^{35}$ the definition is quite broad. It captures products that are commonly understood to be drugs - such as cancer therapies - as well as products that a lay person or healthcare provider may not intuitively consider to be drugs - such as antiperspirant, which is intended to inhibit the body's sweat function. ${ }^{36}$ As the Supreme Court has explained, the FDCA "define[s] 'drug' far more broadly than does the medical profession." "37

Since at least 1984, the FDA has regulated nicotine-containing products intended to assist with smoking cessation as drugs. ${ }^{38}$ Because of the strong causal link between smoking and numerous diseases, the FDA has long considered sellers' claims that a product aids in smoking cessation to be evidence that the product is "intended for use in the . . mitigation, treatment, or prevention of disease." 39 Thus, smoking cessation products such as nicotine-containing gums, lozenges, and transdermal patches (collectively referred to as Nicotine Replacement Therapies, or NRT) are regulated as drugs and require FDA approval before they can be sold. ${ }^{40}$

3221 U.S.C. $\$ 321(\mathrm{~g})(1)$.

3321 C.F.R. $\S 201.128$; see also 21 C.F.R. $\S 801.4$ (providing the same definition for intended use of devices). As discussed later, the FDA is currently in process of revising the regulatory definition of intended use. However, the agency has not proposed changes to, nor has industry objected to, this aspect of the definition. 82 Fed. Reg. 2193, 2198, 2200 (Jan. 9, 2017); 82 Fed. Reg. 14319, 14320 (Mar. 20, 2017).

${ }^{34}$ The FDA's jurisdiction and enforcement authority is also generally linked to a drug's movement (or its components' movement) in interstate commerce. See e.g. 21 U.S.C. $\S \S 321(\mathrm{~g})(1), 331$; Patricia J.

Zettler, Pharmaceutical Federalism, 92 Ind. L.J. 845, 879-80 (2017). However, given modern production processes that typically involve at least components crossing state or national borders, and finished products crossing state and national boundaries to reach customers, this limitation on FDA authority is unlikely to be relevant to nicotine products.

${ }^{35}$ For example, the FDA has explained that, although whole organs intended for transplant "fall[s] within the literal language" of the drug definition, the agency does not intend to regulate them as drugs for various reasons. Statement by the Food and Drug Administration Concerning its Legal Authority to Regulate Human Organ Transplants and to Prohibit Their Sale: Hearing before the Subcommittee on Investigations and Oversight, House Committee on Science and Technology, 98th Cong, 1st Sess. (1983). Likewise in the device context, FDA has applied commonsense limitations by, for instance, declining to construe all exercise equipment - which, of course, is intended to affect the structure or function of the body-to be devices. See, e.g., Letter from Thomas Scarlett, FDA to James V. Lacy, Consumer Product Safety Commission (May 6, 1983).

${ }^{36}$ See, e.g., PETER Hutt, Richard MERrill, \& LeWIS Grossman, FoOd AND DRUg LaW: CASES AND MATERIALS (2013).

${ }^{37}$ United States v. An Article of Drug ... Bacto-Unidisk, 394 U.S. 784, 793, 798 (1969).

${ }^{38}$ Nicorette Approval Date, U.S. FoOD \& DRUG ADMIN., https://www.accessdata.fda.gov/scripts/cder/daf/index.cfm?event=overview.process\&ApplNo=018612 (last visited Aug. 30, 2017).

${ }^{39}$ See, e.g., 82 Fed. Reg. 2193, 2198, 2214 (Jan. 9, 2017).

${ }^{40} 21$ CFR $\S 310.544$. Notably, NRT products are designed to treat tobacco addiction without inducing sustained, long-term use. NRTs have been criticized as being unappealing to current smokers precisely because they have been calibrated not to create dependence. Brent Caldwell, Walt Sumner, \& Julian 
If nicotine is a drug for purposes of NRT, is it also a drug when used in tobacco products themselves? That is the question the FDA raised in 1996, when it tried to regulate tobacco products as drug-delivery devices.

1. The 1996 Rule: The FDA's First Attempt to Regulate Tobacco Products

In 1996, the FDA tried - ultimately unsuccessfully - to argue that because nicotine was a drug "intended to affect the structure or any function of the body," it could regulate tobacco products such as cigarettes and smokeless tobacco as drug-delivery devices. ${ }^{41}$ To support this assertion, the agency pointed to several categories of evidence: tobacco products do, in fact, affect the structure and function of the body in myriad ways; a reasonable tobacco seller would foresee that consumers will use tobacco products to obtain the biological effects of nicotine; and consumers do predominantly use tobacco products for their biological effects. The FDA also relied heavily on recently discovered evidence that the tobacco companies knew that nicotine was addictive (despite their public denials) and deliberately manipulated nicotine levels in tobacco products in order to create and sustain addiction. ${ }^{42}$ This new evidence, in the FDA's view, justified the reversal of its prior position that tobacco products did not qualify as drugs under the FDCA.

Immediately after the FDA asserted jurisdiction over tobacco products, the major tobacco companies filed suit. After four years of litigation, a 5-4 majority of the Supreme Court ruled in FDA v. Brown \& Williamson that the FDA lacked the authority to regulate tobacco products as drugs or devices when those tobacco products are "customarily marketed . . . without ... claims of therapeutic benefit." 43 To reach this conclusion, the Court pointed to the FDCA's "core objective" of ensuring that drugs and devices are safe and effective for their intended use. ${ }^{44}$ Without disagreeing that nicotine-containing tobacco products were "intended to affect the structure or any function of the body," the majority concluded such products could not be regulated as drugs or devices because tobacco products could never meet the "safe and effective" standard. The FDA, in the majority's view, would therefore be required to ban the sale of tobacco products if they came under the FDA's jurisdiction. ${ }^{45}$

The majority's opinion also rested heavily on tobacco's "unique place in American history and society."46 Referring to the economic, social and political significance of the tobacco industry - which it described as "one of the great basic industries of the United States" - the

Crane, A Systematic Review of Nicotine by Inhalation: Is There a Role for the Inhaled Route? 14

NICOTINE \& TOBACCO RESEARCH 1127, 1127 (2012).

${ }^{41}$ See generally, DAVID KESSLER, A QUESTION OF INTENT (2001).

42 FDA v. Brown \& Williamson, 529 US 120, 172 (2000). In 1994, Congress held hearings to investigate the health harms created by tobacco referred to as the Waxman Hearings. At those hearings the 7 CEOs of the major tobacco industries of the time denied that nicotine is addictive and maintained that their manipulation of nicotine levels in products was an effort to enhance flavor, not sustain addiction. Philip J. Hilts, Tobacco Chiefs Say Cigarettes Aren't Addictive, N.Y. TIMES, Apr. 15, 1994.

${ }^{43}$ Food \& Drug Admin. v. Brown \& Williamson Tobacco Corp., 529 U.S. 120, 126 (2000).

${ }^{44}$ Id. at 135.

${ }^{45} I d$. at 137. As the dissent noted, the FDA had interpreted the FDCA differently, concluding that the law gave the FDA the flexibility to regulate tobacco products without banning them. The regulation it proposed would have limited the marketing and sales of tobacco products, but would not have banned them. Id. at 174.

${ }^{46} \mathrm{Id}$. at 159 . 
majority concluded that "Congress could not have intended to delegate a decision of such economic and political significance to [the FDA] in so cryptic a fashion." As a result of the Supreme Court's decision, the FDA was left without the authority to regulate tobacco products "as customarily marketed" absent more explicit authorization from Congress, although it could still regulate other nicotine-containing products, such as NRT, as drugs.

\section{The Tobacco Control Act}

Nine years after the Brown \& Williamson decision, Congress passed - and President Obama signed - the Family Smoking Prevention and Tobacco Control Act, granting the FDA broad jurisdiction over tobacco products. Under the TCA, tobacco products are now a separate regulatory category distinct from drugs and devices. Instead of asking the FDA to assure that tobacco products are "safe and effective"-which, as the majority in Brown \& Williamson noted, is inappropriate for an inherently deadly product - the TCA requires the FDA to regulate tobacco products based on a population-level public health standard. ${ }^{47}$ Under this standard, the FDA must determine that its regulations are "appropriate for the protection of the public health" after considering "the risks and benefits to the population as a whole, including users and nonusers of the tobacco product." 48

The TCA was a negotiated compromise between the tobacco industry and the public health community. The key compromise at its core is this: tobacco products that were already on the market would be "grandfathered," but any new tobacco products must demonstrate either that they are "substantially equivalent" to grandfathered products or that allowing their sale would be "appropriate for the protection of public health."49 This compromise allowed the tobacco industry to keep selling tobacco products, while (at least in theory) ensuring that newly introduced products would benefit, and not harm, public health.

In addition to the premarket review requirements, the TCA also gave the FDA broad authority over other areas of tobacco regulation including health claims, sales and marketing restrictions, and "product standards" including mandated reductions in nicotine levels. ${ }^{50}$ While a full review of the TCA's provisions is beyond the scope of this paper, the law gives the FDA extremely powerful regulatory tools to reduce the death and disease caused by tobacco use.

\section{The Rise of E-Cigarettes}

\footnotetext{
${ }^{47}$ See generally, Family Smoking Prevention and Tobacco Control Act, Pub. L. No. 111-31, 123 Stat. 1776 (2009).

${ }^{48} I d . \S 906,(\mathrm{~d})(1)$.

${ }^{49}$ Id. at $\S 910$. See also Desmond Jenson et al., FDA's Misplaced Priorities: Premarket Review Under the Family Smoking Prevention and Tobacco Control Act, 25 TOBACCO CONTROL 246 (2016).

${ }^{50}$ These restrictions can even be applied to grandfathered products. However, the FDA has recently recognized that their regulatory authority does not extend to zero nicotine products although they state that determinations for such products would be made on a "case-by-case basis" and the "totality of the circumstances." U.S. FOOD \& DRUG ADMINISTRATION, Commonly Asked Questions: About the Center for Tobacco Products, https://www.fda.gov/AboutFDA/CentersOffices/OfficeofMedicalProductsandTobacco/AbouttheCenterfor TobaccoProducts/ucm378205.htm\#14 (last visited Aug. 31, 2017).
} 
The requirements of the TCA applied immediately to certain enumerated tobacco products: cigarettes, smokeless tobacco, and roll-your-own tobacco. ${ }^{51}$ However, the law did not immediately extend the FDA's authority to other types of tobacco products, including ecigarettes, hookah tobacco, cigars, cigarillos, and pipe tobacco. ${ }^{52}$ Instead, the TCA provided that the FDA could "deem" these products, and any other product meeting the statutory definition of a "tobacco product," to be subject to the law's requirements by promulgating a regulation. ${ }^{53}$

Consistent with the process outlined in the TCA, in May 2016, the FDA finalized a rule deeming any product meeting the statutory definition of a "tobacco product," 54 including ecigarettes that contain nicotine, to be subject to the agency's tobacco-related jurisdiction. ${ }^{55}$ Under this regulation, known as the "deeming rule," any product that meets the definition of a new tobacco product is subject to the pre-market review requirements outlined above. ${ }^{56}$ Tobacco products brought within the scope of the FDA's authority by the deeming rule must now include warning labels and comply with various other restrictions, including as a prohibition on false or misleading claims. ${ }^{57}$

The rapid emergence of e-cigarettes was one of the forces driving the FDA to issue the deeming rule. Unlike combustible cigarettes, e-cigarettes deliver nicotine by heating (not burning) a nicotine-containing liquid until it aerosolizes, with the user then "vaping" the resulting aerosol..$^{58}$ The liquid, referred to as an "e-liquid," usually contains nicotine derived from tobacco, a carrier (propylene glycol and/or vegetable glycerin), and flavorings. ${ }^{59}$ First introduced in the United States in 2007, e-cigarette use has risen exponentially. By 2014, almost

5121 U.S.C. $\$ 387 \mathrm{a}(\mathrm{b})$.

${ }^{52} \mathrm{Id}$.

${ }^{53} \mathrm{Id}$.

${ }^{54}$ The deeming rule also includes components and parts, which means "any software or assembly of materials intended or reasonably expected: 1) to alter or affect the tobacco product's performance, composition, constituents or characteristics; or 2) to be used with or for the human consumption of a tobacco product." Deeming Tobacco Products to Be Subject to the Federal Food, Drug, and Cosmetic Act, as Amended by the Family Smoking Prevention and Tobacco Control Act, 81 Fed. Reg. 28974, 29102 (May 10, 2016) [hereinafter Deeming Rule].

${ }^{55} \mathrm{Id}$.

${ }^{56} \mathrm{Id}$. at 28977 . This premarket review process will undoubtedly be much harder for e-cigarette companies because of the amount of data and capital it takes to put forth a new product application, however, the FDA recently delayed the deadline for these new product applications. Press Release, Food and Drug Administration, FDA Announces Comprehensive Regulatory Plan to Shift Trajectory of Tobacco-Related Disease, Death (Jul. 28, 2017) available at https://www.fda.gov/NewsEvents/Newsroom/PressAnnouncements/ucm568923.htm.

${ }^{57} 81$ Fed. Reg. at 28975-6.

${ }^{58}$ Early e-cigarettes were called "cigalikes" and mimicked the size, shape, and design of cigarettes. These products have evolved over time and many do not resemble cigarettes at all; some of the most popular systems include detachable parts that allow the user to customize the vaping experience, including the voltage, the temperature, the size of the tank, etc., and allow for the mixing and switching of new flavors easily. At least some of the newer products appear to be more efficient at delivering nicotine. U.S. FOOD \& Drug AdMINISTRATION, VAPES, E-CIGS, HOOKAH PENS, AND OTHER ElECTRONIC NiCOTINE DELIVERY SYSTEMS (ENDS) (2017) available at https://www.fda.gov/tobaccoproducts/labeling/productsingredientscomponents/ucm456610.htm. ${ }^{59}$ Id. 
half (49\%) of smokers who use daily reported ever having used e-cigarettes, ${ }^{60}$ and e-cigarette use is now more common that cigarette use among high school and middle school students. ${ }^{61}$

As a matter of public health, e-cigarettes hold both promise and peril. Although the longterm health effects of e-cigarettes are unknown, they are likely far less lethal that cigarettes and other combustible products. ${ }^{62}$ If current smokers switched completely from smoking to ecigarette use that would likely produce enormous public health gains. Currently, however, the majority of people who use e-cigarettes are also smoking. ${ }^{63}$ Youth e-cigarette use is also a concern, both because of the effects of nicotine on the developing brain (discussed supra), and because of accumulating evidence that e-cigarette smoking is a gateway to smoking. ${ }^{64}$ Moreover, the history of tobacco product marketing suggests that industry has economic incentives to target the youth population in its marketing, and is likely to do so.

Although not explicitly stated, the FDA's new "comprehensive plan" is built on the assumption that if the nicotine in cigarettes is reduced to non-addictive or minimally addictive levels, many of current smokers will transition to e-cigarettes as the best available substitute. For this reason, the FDA's plan seeks to encourage "innovation" in the e-cigarette market and delays the effective date for some of the deeming rule's more costly requirements. ${ }^{65}$ At the same

${ }^{60}$ Cristine D. Delnevo et al., Patterns of Electronic Cigarette Use Among Adults in the United States, 2016 NiCOTINE \& TOBACCO RESEARCH, 715, 716.

${ }^{61}$ Ahmed Jamal et al., Tobacco Use Among Middle and High School Students - United States, 20112016, 66 MORBIDITY \& MORTALITY WEEKLY REP. 597 (2017).

${ }^{62}$ While the harms of e-cigarettes are likely less than combustible products, there is still potential for significant harms from the products, from the nicotine, from the flavorings, or from the components or parts used to vaporize the liquid. For example, at least one experiment has found that use of e-cigarettes can lead to the stiffening of blood vessels, similar to what smoking combustible cigarettes does, in ways that may raise the likelihood of cardiovascular events. See e.g. Charalambos Vlachopoulos et al., Electronic Cigarette Smoking Increases Aortic Stiffness and Blood Pressure in Young Smokers, 67 J. AM. COLLEGE OF CARDIOLOGY 2082 (2016); Roberto Carnevale et al., Acute Impact of Tobacco vs Electronic Cigarette Smoking on Oxidative Stress and Vascular Function, 150 CHEST 606 (2016).

${ }^{63}$ Charlotte A. Schoenborn, QuickStats: Cigarette Smoking Status among Current Adult E-cigarette Users, by Age Group - National Health Interview Survey, 65 MORBIDITY \& MORTALITY WEEKLY REP. 1177 (2016).

${ }^{64}$ See e.g. Jessica Barrington-Trimis et al., E-Cigarettes and Future Cigarette Use, 138 PEDIATRICs 1 (2016); Adam M. Leventhal et al., Association of Electronic Cigarette Use With Initiation of Combustible Tobacco Product Smoking in Early Adolescence, 314 JAMA 700 (2015); Brian A. Primack et al., Progression to Traditional Cigarette Smoking After Electronic Cigarette Use Among US Adolescents and Young Adults, 169 JAMA PEDIATRICS 1018 (2015). These findings include suggestive evidence that some youth who would not otherwise be likely to become smokers progress to smoking after e-cigarette use. Id. Also, one should note that the history of tobacco marketing suggests that e-cigarette companies, despite statements to the contrary, have strong economic incentives to sell to youth. ROSS HAMMOND, WORLD HEALTH ORgANIZATION, TOBACCO ADVERTISING \& PROMOTION: THE NEED FOR A COORDINATED GLOBAL RESPONSE, 9 (2000).

${ }^{65}$ Press Release, Food and Drug Administration, FDA Announces Comprehensive Regulatory Plan to Shift Trajectory of Tobacco-Related Disease, Death (Jul. 28, 2017) available at https:/www.fda.gov/NewsEvents/Newsroom/PressAnnouncements/ucm568923.htm. Although it is beyond the scope of this paper, we question whether the FDA's approach is well designed to encourage innovation. The extended dates for premarket review apply only to products that were on the market as of August 8, 2016. After that date, any new product cannot be sold until it undergoes premarket review by 
time, the FDA recognizes that e-cigarettes cannot be completely unregulated. The deeming rule already prohibits unsubstantiated health claims, bars sales to minors, and requires e-cigarette companies to disclose their ingredient lists to the FDA; the FDA has pledged to go further and develop product standards relating to battery safety and child-proofing. ${ }^{66}$

Regardless of where one stands on the "harm reduction" debate surrounding e-cigarettes, we think all sides should be able to agree that there is a role for reasonable regulation (although there may be disagreement on the proper extent of regulation). A complete lack of regulation invites problems that have already been observed in the e-cigarette market, which was unregulated until this year: false and misleading claims, ${ }^{67}$ inaccurate labeling, ${ }^{68}$ dangerously shoddy product quality, ${ }^{69}$ unabashed marketing to youth, ${ }^{70}$ and more. However, even with full implementation of the deeming rule, it appears that one portion of the e-cigarette market may remain completely unregulated, at least for now: synthetic nicotine.

\section{The Emergence of Synthetic Nicotine}

The deeming rule applies only to e-cigarettes that contain nicotine "made or derived from tobacco."71 In the last few years, however, over a dozen e-cigarette brands have begun to sell synthetic nicotine, developed in a lab without the use of tobacco plants. ${ }^{72}$ This product is chemically identical to the nicotine found in tobacco plants - and similarly addictive — but falls outside of the FDA's tobacco-related authority.

Sellers of synthetic nicotine claim it is an important advance, because tobacco-derived nicotine inevitably also contains some contaminants - including potentially carcinogenic onesfrom tobacco plants, whereas synthetic nicotine is "pure." For the same reason, they contend that synthetic nicotine offers a "comparatively clean flavor" when used in e-liquids.

Although the technology to create synthetic nicotine has existed since the 1940s, the high cost of production has limited its commercial use. Now, however, more efficient production methods have been developed, and some companies are selling synthetic nicotine at prices comparable to other e-liquids. For example, we observed that one company sells $60 \mathrm{~mL}$ of its

the FDA. Thus, the extended dates provide a reprieve to e-cigarette companies that were worried they would be unable to comply with the FDA's requirements - but does nothing to encourage innovation. ${ }^{66} I d$. The FDA also states that it intends to propose a rule for the regulation of flavors in newly deemed products.

${ }^{67}$ Elizabeth Klein et al., Online E-cigarette Marketing Claims: A Systematic Content and Legal Analysis, 2 TOBACCO REGULATORY SCIENCE 252 (2016).

${ }^{68}$ Kelly Buettner-Schmidt et al., Electronic Cigarette Refill Liquids: Child-Resistant Packaging, Nicotine Content, and Sales to Minors, 31 J. PEDIATRIC NuRsing 373 (2016).

${ }^{69}$ Jamie Harshman et al., Burns Associated with E-cigarette Batteries: A Case Series and Literature Review, 2017 CAN. J. EMERGENCY MED. 1.

${ }^{70}$ Jennifer C. Dukes et al., Exposure to Electronic Cigarette Television Advertisements Among Youth and Young Adults, 134 PEDIATRICS 1 (2014).

${ }^{71}$ Deeming Tobacco Products to Be Subject to the Federal Food, Drug, and Cosmetic Act, as Amended by the Family Smoking Prevention and Tobacco Control Act, 81 Fed. Reg. 28974 (May 10, 2016).

${ }^{72}$ Sarah Zhang, E-Cigs Are Going Tobacco-Free with Synthetic Nicotine, WIRED (June 27, 2016), https:/www.wired.com/2016/06/vaping-industry-wants-go-post-tobacco-synthetic-nicotine/. 
"mangolito" flavor e-juice with tobacco-derived nicotine for $\$ 24.99$, and it sells the same amount of the same flavor e-juice with synthetic nicotine for $\$ 27.99 .{ }^{73}$

One company asked the FDA for clarification on whether synthetic nicotine would fall within the deeming rule's scope. While the FDA has hedged and said that synthetic nicotine products will be evaluated on a "case-by-case basis," "74 we think it clear that e-cigarettes that use only synthetic nicotine - which, by definition, is not "made or derived from tobacco" 75 - are not tobacco products under the TCA. Thus, these products are not subject to any of the deeming rule's regulations - no premarket approval requirements, no warning labels, no prohibition on health-related claims, and so forth. This is, we believe, a problematic regulatory gap. As discussed in the following section, however, the FDA has a viable option for closing it: classifying synthetic nicotine products as drugs.

\section{The Legal CASE For Regulating Synthetic NiCOTINe AS A DRUG}

Synthetic nicotine - because it, by definition, is not "made or derived from tobacco" is not a tobacco product under the TCA. Some in the e-cigarette industry have claimed synthetic nicotine's escape from the requirements of the deeming rule and the FDA's tobacco regulatory scheme as a "victory,"77 seemingly concluding that if synthetic nicotine is not a tobacco product, it is not subject to any FDA regulation. The question of whether synthetic nicotine products are tobacco products, however, is not the end of the inquiry into the FDA's jurisdiction. Examination of the relevant statutory provisions, case law, and regulations, as well as other agency interpretations of the law, suggests that synthetic nicotine should be considered to be a drug under the FDCA. ${ }^{78}$

${ }^{73}$ EJUICES.COM, https://www.ejuices.com/products/mangolito?variant=25544343112 (last visited Aug. 31, 2017); see also EJUICES.COM, https://www.ejuices.com/products/mangolito-tfn?variant=27307416072 (last visited Aug. 31, 2017).

${ }^{74}$ U.S. FoOD \& DRUG ADMINISTRATION, Commonly Asked Questions: About the Center for Tobacco Products, https:/www.fda.gov/AboutFDA/CentersOffices/OfficeofMedicalProductsandTobacco/AbouttheCenterfor TobaccoProducts/ucm378205.htm\#14 (last visited Aug. 31, 2017).

${ }^{75} 21$ U.S.C. $\S 321(\mathrm{rr})(1)$.

${ }^{76} \mathrm{Id}$.

${ }^{77}$ Tony Ottomanelli II, Update: Nicopure v. FDA Lawsuit, VAPING Post (Dec. 20, 2016), http://www.vapingpost.com/2016/12/20/update-nicopure-v-fda-lawsuit/.

${ }^{78}$ Depending on how a synthetic nicotine product is marketed - either as a liquid alone or as a liquid combined with a mechanism for delivery - it might be categorized as either a drug or a drug-device combination product. However, this Article generally describes synthetic nicotine as a drug. Even if a given synthetic nicotine product is a drug-device combination product, the FDA would likely regulate the product as a drug. This is because, for combination products, the FDA must determine the product's "primary mode of action" - that is, the component that "provides the most important therapeutic action"-and oversee the product accordingly. See 21 U.S.C. $\S 353(\mathrm{~g}) ; 21$ C.F.R. $\S 3.2$. For synthetic nicotine products, it is the nicotine liquid that creates an effect in the body, and any device component is intended solely to deliver the nicotine. Therefore, as with drug-device combination products like prefilled syringes, the FDA is likely to regulate combination synthetic nicotine products as drugs. Additionally, the relevant language in the definitions of "drug" and "device" in the FDCA are nearly identical, with both focusing on whether an "article" is "intended for use" in diagnosing, curing, mitigating, treating, or 


\section{A. The Flexibility to Regulate Synthetic Nicotine as Drug}

To understand why synthetic nicotine is a drug within the FDA's jurisdiction, it is first necessary to consider whether the courts have limited the FDA's flexibility to interpret the statutory definition of a drug in the context of synthetic nicotine. The FDCA defines a "drug" as an "article" "intended for use in the diagnosis, cure, mitigation, treatment, or prevention of disease" or "intended to affect the structure or any function of the body."79 Although courts (and the FDA) have generally construed this definition quite broadly, the definition does not cover "customarily marketed" tobacco products. As discussed in Section I.B.1., supra, in FDAv. Brown \& Williamson, a majority of the Supreme Court concluded that - under federal law before the enactment of the TCA - Congress had "clearly precluded the FDA from asserting jurisdiction to regulate tobacco products" as drugs or devices, when those tobacco products are "customarily marketed ... without . . claims of therapeutic benefit." 80

This conclusion also has been followed after the enactment of the Tobacco Control Act. In Sottera v. FDA, an e-cigarette company sued the FDA after the agency sought to regulate the company's products as drug-device combinations. ${ }^{81}$ Relying on Brown \& Williamson, the D.C. Circuit concluded that, because the e-cigarettes at issue had tobacco-derived nicotine and therefore met the TCA's definition of a "tobacco product," the FDA must regulate them as tobacco products, so long as they are "customarily marketed." 82 That is, according to Sottera, the FDA lacked the discretion to regulate the e-cigarettes pursuant to its drug and device authorities, provided that the seller was not making "therapeutic claims." 83

Consistent with Sottera, in a 2017 final rule on the meaning of "intended use," the FDA clarified that it will regulate products made or derived from tobacco as drugs or devices only when they are intended for disease treatment or prevention (e.g., if they are marketed with smoking cessation claims) or if they are marketed with claims that the product affects the

preventing disease, or is "intended to affect the structure or any function of the body." 21 U.S.C. $\$ 312(\mathrm{~g})$, (h). Thus, FDA jurisdiction over synthetic nicotine, and many relevant requirements that come with such jurisdiction, do not turn on whether a given product would be a drug or drug-device combination.

${ }^{79} 21$ U.S.C. $\S 321(\mathrm{~g})(1)$.

${ }^{80}$ Food \& Drug Admin. v. Brown \& Williamson Tobacco Corp., 529 U.S. 120, 126 (2000).

${ }^{81}$ Sottera, Inc. v. Food \& Drug Admin., 627 F.3d 891, 893 (D.C. Cir. 2010).

${ }^{82} \mathrm{Id}$. The reasoning of Sottera was questionable. As discussed, the Brown \& Williamson decision focused on the unique history of tobacco products and tobacco regulation. E-cigarettes were, of course, not a part of that history, and the Supreme Court certainly did not have e-cigarettes (which had not been introduced in the United States yet) in mind when it wrote its decision. Thus, the FDA could have reasonably concluded that Brown \& Williamson didn't constrain its discretion with regards to other nicotine-containing products. Likewise, there's no evidence that Congress, when it passed the TCA, was thinking about e-cigarettes at all — and certainly none that it intended for them to be regulated only as tobacco products.

${ }^{83} \mathrm{Id}$. 
structure or function of the body that were not commonly and legally made at the time Brown \& Williamson was decided. ${ }^{84}$

But, crucially, these limits on the agency's flexibility to regulate tobacco products as drugs, devices, or drug-device combination products do not apply to synthetic nicotine products. Synthetic nicotine e-liquids are not made or derived from tobacco, meaning they generally are not tobacco products - in both the FDA's and industry's view. ${ }^{85}$ Additionally, many of the concerns about the application of the FDA's drug authorities to tobacco products that drove the majority's decision in Brown \& Williamson are not present for synthetic nicotine. If synthetic nicotine e-cigarettes live up to advocates' claims that they are a safe(r) way to use nicotine, these products should not provoke the same concern that they cannot satisfy the "safe and effective" standard needed for drug approval as cigarettes did. Similarly, the synthetic nicotine industry is a nascent one, without the economic, social, and political significance of the tobacco industry that helped motivate the majority's conclusion in Brown \& Williamson that Congress did not intend for the FDA to regulate tobacco products. Finally, Congress explicitly chose to apply the TCA's requirements only to "tobacco products," declining to direct the FDA to regulate drugs containing nicotine, such as the smoking cessation products long regulated as drugs, under the new TCA scheme. ${ }^{86}$ Therefore, unlike in the FDA's attempt to regulate traditional tobacco products as drug-device combination products in the 1990's, the FDA regulating synthetic nicotine as a drug would not raise concerns that the FDA was contravening the will of Congress.

This means that, as with any other novel product, the FDA has considerable flexibility to determine whether a synthetic nicotine product falls within the drug definition. ${ }^{87}$ That is, the inquiry for determining whether a particular synthetic nicotine product is a drug is the same as it is for any non-tobacco product. There is no need to consider whether the synthetic nicotine

${ }^{84} 82$ Fed. Reg. 2193, 2198, 2200 (Jan. 9, 2017). The FDA delayed the effective date of this final rule until March 2018 based on concerns raised about a different aspect of the FDA's revisions to the definition of intended use. 82 Fed. Reg. 14319, 14320 (Mar. 20, 2017).

${ }^{85}$ See, e.g., Sarah Zhang, E-Cigs Are Going Tobacco-Free with Synthetic Nicotine, WIRED (June 27, 2016), https://www.wired.com/2016/06/vaping-industry-wants-go-post-tobacco-synthetic-nicotine/; U.S. Food \& Drug Admin., Commonly Asked Questions: About the Center for Tobacco Products, https://www.fda.gov/AboutFDA/CentersOffices/OfficeofMedicalProductsandTobacco/AbouttheCenterfor TobaccoProducts/ucm378205.htm\#14; cf. NEXTGENERATIONLABS, http://www.nextgenerationlabs.com/ (last visited Aug. 31, 2017) (marketing a product called TFN®, or "Tobacco Free Nicotine"). Because dietary supplements can be intended to affect the structure of function of the body without becoming drugs under the law, it is also worth noting that synthetic nicotine products are not likely to meet the definition of a dietary supplement. Among other reasons, to be a dietary supplement, a product must be "intended for ingestion." 21 U.S.C. § 321(ff)(2)(A)(i). Currently marketed synthetic nicotine products are intended for inhalation, not ingestion.

${ }^{86}$ See Tobacco Control Act $\S \S 911(\mathrm{c}), 911(\mathrm{~g})(4), 918$.

${ }^{87}$ Cf. United States v. Article of Drug . . . Bacto-Unidisk . ., 394 U.S. 784 (1969) (giving the FDA wide latitude in how it interprets the drug and device definitions in the FDCA); Peter Barton Hutt, Philosophy of Regulation under the Federal Food, Drug and Cosmetic Act, 28 Food Drug Cosmetic L J 177, 178 (1973) ("the Act must be regarded as a constitution" that "establishes a set of fundamental objectives set of fundamental objectives - safe, effective, wholesome, and truthfully-labeled products - without attempting to specify every detail of regulation"). 
product is "customarily marketed," nor are there any tobacco-specific limits on the agency's authority to regulate synthetic nicotine products as drugs.

\section{B. The Intended Use of Synthetic Nicotine}

Because Brown \& Williamson and Sottera do not apply to products like synthetic nicotine that are not "tobacco products," the determining factor for whether synthetic nicotine is a drug is, simply, its intended use. Although the precise rule for determining intended use is currently the subject of debate, ${ }^{88}$ myriad kinds of evidence may be relevant to the analysis. ${ }^{89}$ Most clearly, a seller's representations about its product might be evidence of the seller's intended use. ${ }^{90}$ But the plain language of the statute, which describes uses as "intended" rather than "labeled," "promoted," or "claimed," makes apparent that evidence other than a sellers' representations also can be relevant. ${ }^{91}$

The available evidence for synthetic nicotine suggests that there is strong case for FDA to conclude that these products fall within the FDCA's broad definition of a drug. Companies' representations about their products, the design of the products, and the circumstances surrounding their distribution all support this conclusion. Moreover, when sellers have challenged the FDA's authority to regulate a product — or challenged the FDA's determination about which category a product falls within — courts have generally sided with the FDA. ${ }^{92}$ Thus, even if one (or two) of these sources of evidence about the intended uses of synthetic nicotine were unpersuasive to courts, courts may be likely to agree with, or defer to, the agency's interpretation that synthetic nicotine is a drug. ${ }^{93}$

To be clear, determining a product's intended use is a product specific-inquiry. The features of the particular product at issue, including the seller's representations about the

\footnotetext{
${ }^{88}$ See 82 Fed. Reg. 14319, 14320 (Mar. 20, 2017) (delay of effective date for final rule); Petition to Stay and for Reconsideration, https://www.regulations.gov/document?D=FDA-2015-N-2002-1977; see also Lewis A. Grossman, Food, Drugs, and Droods: A Historical Consideration of Definitions and Categories in American Food and Drug Law, 93 CORNELL L. REV. 1091, 1108 (2008) ("Indeed, modern food and drug law is bedeviled by the question of how the phrase "intended to" in these definitions should be construed.").

${ }^{89}$ See, e.g., United States v. Storage Spaces Designated Nos. 8 \& 49 Located at 277 E. Douglas, Visalia, Cal., 777 F.2d 1363, 1366 (9th Cir. 1985) ("This intent may be derived or inferred from labeling, promotional material, advertising, or any other relevant source."); see also FDA v. Brown \& Williamson Tobacco Corp., 529 U.S. 120, 170 (2000) (dissenting opinion) The [FDCA] . . does not use the word 'claimed'; it uses the word 'intended"'); Grossman, supra note 88 at 1109 ("In the years following the [enactment of the 1906 Pure Food and Drugs Act] . . the FDA and the courts looked to evidence other than drug sellers' explicit claims to determine the "intended use" of products").

${ }^{90}$ See, e.g., Grossman, supra note 88, at 1108.

${ }^{91} 21$ USC 321(g);

92 See, e.g., Adam Candeub, Digital Medicine, the FDA, and the First Amendment, 49 GA. L. REV. 933, 957 (2015); Patricia J. Zettler, What Lies Ahead for FDA Regulation of tDCS Products, 3 J. LAW BIOSCI. 318, 319 (2016); but see Bracco Diagnostics, Inc. v. Shalala, 963 F. Supp. 20, 28 (D.D.C. 1997) (rejecting the FDA's classification of a specific product because the agency did not treat like products similarly). ${ }^{93}$ The majority's conclusion in Sottera that FDA was not owed deference because the question at issue in that case was not one of statutory interpretation, but rather one of interpreting Brown \& Williamson is not relevant to synthetic nicotine product because they are not tobacco products.
} 
product, must be assessed individually. ${ }^{94}$ But in this Article, we do not take on the task of fully examining individual products or identifying specific products that meet the definition of a drug. Rather, we demonstrate that based on the illustrative examples identified below, it appears that, synthetic nicotine products generally fall within the drug definition.

\section{Sellers' Representations}

Sellers' claims that their products diagnose, cure, mitigate, treat, or prevent disease (disease claims) or that their products affect the structure or function of the body (structure/function claims) are, perhaps, the evidence that FDA most commonly, and least controversially, relies on as evidence of intended use. ${ }^{95}$ These claims might come in the form of written statements or graphic representations in product labeling or advertising, including on websites or social media, or oral statements made by or on behalf of the seller. ${ }^{96}$ Additionally, both disease and structure/function claims might be explicit or implicit. For example, "controls diabetes" is an explicit claim that a product treats diabetes, while "controls blood sugar" implies that a product treats diabetes through referencing a characteristic symptom or sign of the disease. ${ }^{97}$ Likewise, a structure/function claim might be implicit—as one example, "charge your mind" does not explicitly state that a product will affect brain function or structures, but implies that it will..$^{98}$

Reviewing the websites and social media accounts of synthetic nicotine sellers suggests that companies routinely make representations that the FDA could reasonably construe as either disease or structure/function claims. Smoking cessation claims are the most obvious kind of disease claims that purveyors of synthetic nicotine might make. ${ }^{99}$ This is because many consumers believe that e-cigarettes-whether using synthetic nicotine or nicotine derived from

\footnotetext{
${ }^{94}$ See, e.g., Zettler, supra note 92 , at 319.

${ }^{95}$ Cf. Petition for Stay of Intended Use Rule ("From the outset, the 'intended use' prong of the drug definition related to the seller's claims for its products."). In recent years, courts have become increasingly willing to find that the FDA's policies on "off-label" promotion of approved drug products, which rely on sellers' claims as evidence of intent, are in conflict with First Amendment protections for commercial speech. Scholars have expressed concern that if the logic of these decisions is extended, the entire structure of the FDCA - including, possibly, the reliance on sellers' claims as evidence of intended use for the purposes of defining a product - may be eroded. Christopher Robertson \& Aaron S. Kesselheim, Regulating Off-Label Promotion-A Critical Test, 375 NEw ENG. J. MED. 2313, 2315 (2016). Courts, however, have thus far not concluded that the First Amendment protects the promotion of unapproved drugs or bars the FDA from considering sellers' representations in determining whether the FDA has jurisdiction over a product.

${ }^{96}$ Cf. Nathan Cortez, The Statutory Case against Off-Label Promotion, 83 U. CHI. L. REV. Online 124, 126 (2016) (explaining the varied forms that prescription drug promotion takes).

9721 C.F.R. § 101.93(g)(2)(ii); 65 Fed. Reg. 1000, 1013 (Jan. 6, 2000).

${ }^{98}$ See Zettler, supra note 92 at 320.

${ }^{99}$ Cf. 82 Fed. Reg. 2193, 2198, 2214 (Jan. 9, 2017) (explaining that smoking cessation claims are disease claims); Johnson Creek Warning Letter (Sept. 8, 2010), https://wayback.archiveit.org/7993/20161023101826/http://www.fda.gov/ICECI/EnforcementActions/WarningLetters/2010/ucm 225206.htm (same).
} 
tobacco - are effective smoking cessation aids. ${ }^{100}$ Consistent with this market potential, some sellers and sellers of synthetic nicotine appear to represent their products as intended for smoking cessation.

For example, the CEO of Vapeix, in a press release announcing its partnership with Next Generation Labs to develop products using synthetic nicotine, stated, "This technology alliance will not only open the door for an entirely new, non-tobacco vape market, it aligns us closer to the pharmaceutical industry when combining the benefits from Vapeix Powered technologies with [synthetic nicotine], which can potentially result in future cessation tools for adult smokers." ${ }^{101}$ Indeed, in Next Generation Labs' patent application for its method of synthesizing nicotine, it wrote that its product could be used "in vapor for treatment of smoking cessation [sic]." 102

That said, because it is well-known that the FDA considers smoking cessation claims to be evidence that any product, including a tobacco product, is a drug, synthetic nicotine companies may avoid such claims. More common may be representations that synthetic nicotine e-cigarettes are less harmful than tobacco products. One seller's blog, for example, states that their synthetic nicotine contains, "[n]o [c]arcinogenic or other tobacco combustion substances." 103 Similarly, another seller of synthetic nicotine claims "since [its product] is completely synthetic, [it] does not contain any of some of the most harmful chemicals typically found as contaminants in tobacco-derived nicotine." "104 These kinds of statements would be "modified risk" claims if synthetic nicotine were a tobacco product-meaning these claims suggest the product reduces harm or the risk of tobacco-related disease - and would require FDA approval if made about tobacco products. ${ }^{105}$ But outside of the context of tobacco products, modified risk claims are arguably disease claims. Although on their face modified risk claims are simply comparative claims about differences between synthetic nicotine and tobacco-derived

\footnotetext{
100 The evidence to support this assertion is mixed, and more research is currently underway. Compare Sara Kalkhoran \& Stanton A. Glantz, E-cigarettes and Smoking Cessation in Real-World and Clinical Settings: A Systemic Review and Meta-Analysis, 4 LANCET RESPIRATORY MED. 116, 116 (2016) (concluding that "[a]s currently being used, e-cigarettes are associated with significantly less quitting among smokers") with Shu-Hong Zhu et al., E-Cigarette Use and Associated Changes in Population Smoking Cessation: Evidence from US Current Population Surveys, BMJ (2017) (online ahead of print), http://www.bmj.com/content/358/bmj.j3262 (finding that "[t] he substantial increase in e-cigarette use among US adult smokers was associated with a statistically significant increase in the smoking cessation rate at the population level").

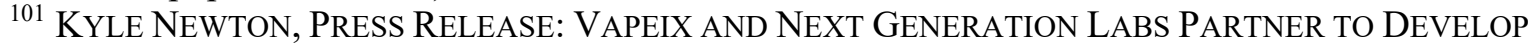
CONNECTED VAPE SYSTEM, (Jul. 26, 2016), https://www.vapeix.io/press-release-vapeix-next-generationlabs-partner-develop-connected-vape-system/.

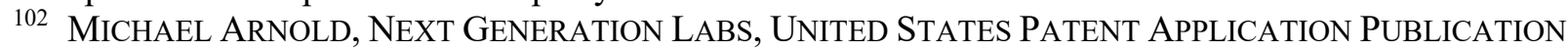
\#US 2016/0115150 AI (Apr. 28, 2016), http://www.freepatentsonline.com/20160115150.pdf.

${ }^{103}$ DANIEL D. SANTOS, NTN - A NEW GENERATION OF NiCOTINE (Nov. 25, 2016) http://blog.hiliq.com/ntn-a-new-generation-of-nicotine/.

104 AUSTER, https://www.auster.com/pages/tfn\# (last visited Aug. 31, 2017).

10521 USC $387 \mathrm{k}$.
} 
nicotine products, they imply that synthetic nicotine products reduce the risk of disease and other health harms well-known to be associated with tobacco and nicotine use. ${ }^{106}$

Synthetic nicotine sellers might also make disease claims unrelated to the diseases associated with the use of traditional tobacco products. For example, one seller of synthetic nicotine posted on its Facebook page a customer review that touted the seller's "glacier, minty menthol" flavor as "definitely something you vape when you're like sick" because "it opens me up." 107

But synthetic nicotine companies perhaps most clearly represent their products as affecting the structure or function of the body. For instance, several sellers claim that their synthetic nicotine has "the same biological impact as tobacco derived nicotine." 108 This statement is an express structure/function claim by asserting that the product has a "biological impact" on the body. Moreover, by comparing synthetic nicotine to tobacco-derived nicotinewhich is well-known to be a stimulant and to be addictive - this statement would imply an effect on the structure or function of the body even without the "biological impact" language.

Similarly, labeling products with different nicotine strengths, as many companies do, ${ }^{109}$ or claiming that one benefit of synthetic nicotine is that its flavor profile "allow[s] for the addition of a higher nicotine content," implies that nicotine will affect the structure or function of the body - otherwise, why have higher strengths of the ingredient, while also asserting that the nicotine is "tasteless and odorless"? ${ }^{110}$ Even merely claiming nicotine as an ingredient, which all synthetic nicotine companies seem to do, can be construed as a structure/function claim because of nicotine's well-known impact on the body. ${ }^{111}$ Indeed, nicotine's impact on the body is described in warnings and disclaimers on the companies' websites. ${ }^{112}$

In some circumstances, courts, arguably, have concluded that structure/function claims must have some therapeutic implication to place a product within the FDA's jurisdiction. ${ }^{113}$ To

${ }^{106}$ Cf. 81 Fed. Reg. 28974, 29037 (May 10, 2016) (explaining why smoking cessation claims are not simply behavior modification claims, but are instead disease claims).

${ }^{107}$ SQN, https://www.facebook.com/sqnvapor/ (last visited Aug. 31, 2017); NKTR Ice E-Liquid - 20\% Off Code, (Jul. 14, 2017) https://www.youtube.com/watch?v=RCA_42S4IV0.

${ }^{108}$ NEXT GENERATION LABS, http://www.nextgenerationlabs.com/ (last visited Aug. 31, 2017), See also DANIEL D. SANTOS, NTN - A NEW GENERATION OF NiCOTINE (Nov. 25, 2016) http://blog.hiliq.com/ntna-new-generation-of-nicotine/; VAPEREV, http://shop.vaperev.com/tfn-liquids.html (last visited Aug. 31, 2017); EJUICE DIRECT, https://ejuicedirect.com/collections/tfn-nicotine (last visited Aug. 31, 2017).

${ }^{109}$ See, e.g., VAPEREV, http://shop.vaperev.com/tfn-liquids.html (last visited Aug. 31, 2017).

${ }^{110}$ NEXT GENERATION LABS, http://www.nextgenerationlabs.com/ (last visited Aug. 31, 2017).

${ }^{111}$ Cf. 65 Fed. Reg. 1000 (Jan. 6, 2000) (explaining that describing a product with a commonly known drug name, such as "herbal Prozac," can be construed as a disease claim).

${ }^{112}$ See, e.g., NEXT GENERATION LABS, http://www.nextgenerationlabs.com/disclaimers/ (last visited Aug. 31, 2017).

${ }^{113}$ See, e.g., United States v. Article . . Consisting of 216 Cartoned Bottles, More or Less, Sudden Change, 409 F.2d 734 (2d Cir. 1969); United States v. Article Consisting of 36 Boxes, More or Less, Labeled 'Line Away Temp. Wrinkle Smoother, Coty,' 415 F.2d 369 (3d Cir. 1969); United States v. Article of Drug 47 Shipping Cartons, More or Less, 'Helene Curtis Magic Secret,' 331 F. Supp. 912 (D. M.D. 1971); Anna Wexler, A Pragmatic Analysis of the Regulation of Consumer Transcranial Direct Current Stimulation (tDCS) Devices in the United States, 2 J. L. \& BIOSCI. 669 (2015); Zettler, supra note 92 at 321 . 
the extent such a limitation exists, however, it is not relevant to the kinds of structure/function claims that synthetic nicotine companies make about their products. ${ }^{114}$ Courts have described structure/function claims with therapeutic implications to be those claims that suggest that the "product will affect the structure of the body in some medical- or drug-type fashion."115 Claims related to nicotine or a biological impact on the body would seem to easily meet this standard of a "drug-type" effect because nicotine is the active ingredient in drugs approved for smoking cessation, ${ }^{116}$ and also because nicotine's stimulant effects and additive properties are well-known and similar to the effects of other drugs. ${ }^{117}$

Synthetic nicotine companies, thus, appear to routinely represent their products as being intended to mitigate, treat, or prevent disease or to affect the structure or function of the body such that their products fall within the definition of a drug. Although some companies include statements on their website disclaiming any intent that synthetic nicotine products will diagnose, treat, cure, or prevent disease, such disclaimers may not be sufficient to correct the overall impression that companies have created that synthetic nicotine products are intended for therapeutic use. ${ }^{118}$ Moreover, on their face, these disclaimers do nothing to dispel the impression that synthetic nicotine products are intended to affect the structure or function of the body. The FDA, therefore, could reasonably conclude — based on companies' representations - that synthetic nicotine products are drugs under the FDCA, and there would be ample evidence to support that interpretation if it were challenged in court.

\section{Product Design}

As the above analysis shows, synthetic nicotine products are frequently marketed with disease or structure/function claims that cause them to fall within the definition of a drug. But

\footnotetext{
${ }^{114}$ Additionally, as one of the authors has argued elsewhere, it is not clear that courts, in fact, consider a therapeutic implication to be necessary outside the context of tobacco products. See Zettler, supra note 92 at 319 n. 18; see also Food \& Drug Admin. v. Brown \& Williamson Tobacco Corp., 529 U.S. 120, 162 (U.S. 2000) (Breyer, J., dissenting). Moreover, the FDA has a long, and established, history of interpreting "pure" structure/function claims to cause products to fall within the definition of a drug (or the definition of a dietary supplement), to which courts may be likely to defer. See, e.g., Chevron, U.S.A., Inc. v. Nat. Res. Def. Council, Inc., 467 U.S. (1984); 65 Fed. Reg. 1000 (Jan. 6, 2000).

${ }^{115}$ Sudden Change, 409 F.2d at 742.

${ }^{116}$ See, e.g., NicoDerm Labeling, https://www.accessdata.fda.gov/drugsatfda_docs/label/2016/201650rig1s038lbl.pdf.

${ }^{117}$ Cf. Warning Letter to ALV Supplement Direct (describing caffeine powder as a drug), https:/www.fda.gov/iceci/enforcementactions/warningletters/2016/ucm489374.htm.

118 See, e.g., United States v. Undetermined Quantities of an Article of Drug Labeled as "Exachol”, 716 F.Supp. 787, 791 (S.D.N.Y. 1989) ("FDA is not bound by the vendor's subjective claims of intent ... [a]n article intended to be used as a drug will be regulated as a drug ... even if the product's labeling states that it is not a drug"); United States v. Storage Spaces Designated Nos. 8 and 49, 777 F.2d 1363, 1366 n.5 (9th Cir. 1985) (concluding that products labeled as "incense"' and "not for drug use" were drugs under the FDCA where the "overall circumstances" demonstrated the seller's intent that products be used as cocaine substitutes); 82 Fed. Reg. 2193, 2199 (Jan. 9, 2017) ("FDA intends to view such disclaimers skeptically because . . . In most cases . . . FDA does not believe that disclaimers will sufficiently mitigate consumer confusion due to the product's claimed therapeutic benefit.").
} 
even if current marketing were modified such that sellers' claims did not provide evidence of a drug's intended use, ${ }^{119}$ the design of synthetic nicotine products - and in particular the fact that the products contain nicotine - also provides evidence that these products are intended to affect the structure or function of the body. For example, at least one FDA attorney has concluded that "if you put a 'drug-like' ingredient in a [product] and you know that the ingredient will affect the structure and function of the human body, then you [sellers] must have presumed for that effect to take place." 120

In various circumstances, the FDA has relied on a product's ingredients or other aspects of its design to infer the seller's intent that it be used to affect the structure or function of the body. Perhaps most relevant, the FDA made this argument to support its (later vacated) 1996 rule asserting jurisdiction over tobacco products. In its jurisdictional statement accompanying the 1996 rule, the FDA explained both that nicotine, in fact, does affect the structure or function of the body - through its addictive, mood-altering, and weight-loss properties - and that tobacco sellers intend this outcome. ${ }^{121}$ The agency based its conclusion about sellers' intent on five central findings, three of which clearly relate to product design: that the biological effects of nicotine are "so widely known and accepted that it is foreseeable to a reasonable seller that cigarettes and smokeless tobacco ... will be used by consumers for [those] purposes"; that sellers "design their products to provide consumers with a pharmacologically active dose of nicotine," and; "[a]n inevitable consequence of the design of cigarettes and smokeless tobacco to provide consumers with a pharmacologically active dose of nicotine is to keep consumers using [the products] by sustaining their addiction to nicotine."122

Although a majority of the Supreme Court ultimately concluded that FDA lacked authority to regulate the nicotine in tobacco products as drugs in Brown \& Williamson, that decision was based on the Court's conclusion that, because of issues unique to tobacco products,

\footnotetext{
${ }^{119}$ It is worth noting that merely removing the kinds of claims discussed in section II.B.1 supra may not be sufficient to demonstrate a new intended use for the products. In at least one case, involving a prostaglandin derivative for eyelash growth, the Federal Circuit seemed to conclude that a company's past claims that its product affected the structure of eyelashes were relevant to an intended use analysis because the company did not materially alter its product's formulation, did not disavow its previous claims, and continued to make claims referencing eyelash structure, albeit implicit claims. Allergan, Inc. v. Athena Cosmetics, Inc., 738 F.3d 1350, 1357 (Fed. Cir. 2013). Although it was a California law, rather than the FDCA, at issue in the case, the California law incorporated provisions of the FDCA and the intended use analysis was the same as it would have been under the FDCA. See id.

${ }^{120}$ T. Scarlett, remarks at 1976 Cosmetic Toiletries \& Fragrances Association Scientific Conference quoted in FDC Reports at B-3 (Nov. 8, 1976); see also 82 Fed. Reg. 2193, 2208 (Jan. 9, 2017) (explaining that the FDA has relied on product ingredients as circumstantial evidence of intended use); Warning Letter from Ronald M. Pace, FDA to Peter Erlikh, INZ Distributors, Inc. (Aug. 23, 2010), https://wayback.archive-

it.org/7993/20170112004414/http://www.fda.gov/ICECI/EnforcementActions/WarningLetters/2010/ucm 225432.htm (concluding that "Magic Power Coffee" was a drug in part because it contained an analogue of the active ingredient in Viagra).

${ }^{121} 1996$ Jurisdictional Statement at 44630, https://www.gpo.gov/fdsys/pkg/FR-1996-08-28/pdf/X9620828.pdf.

${ }^{122}$ Id. The other two factors - consumer intent and seller knowledge of consumer intent—are discussed in Section II.B.3 infra.
} 
Congress's did not intend for the FDA to regulate tobacco products as drugs. ${ }^{123}$ The Court did not opine on - or disagree with - the FDA's use of product design as evidence of intended use. ${ }^{124}$ Brown \& Williamson, therefore, does not preclude the FDA from relying on these sources as evidence of intended use.

Outside of the tobacco products context, although no court has squarely faced the issue of whether product design, alone, can be evidence of intended use, courts have seemed open to the idea. ${ }^{125}$ For example, in Sudden Change, a case about whether a wrinkle cream was a cosmetic intended only to affect appearance, or a drug intended to affect the structure or function of the skin, the Second Circuit opined that a skin cream would be a cosmetic rather than a drug if the seller "avoids . . . claiming to affect the structure or function of the skin in some physiological . . . way" and "no actual physical effect exists." ${ }^{26}$ Similarly, in a case about whether a product was a vitamin or a drug, although the court did not agree with the FDA's argument that all products with vitamin doses higher than the recommended daily intake were drugs, the Second Circuit did not reject the agency's argument on the ground that FDA could not consider product design, and specifically dosage. ${ }^{127}$ Instead, the court rejected the agency's conclusion that consumers could not be using such high dose products "for nutritional purposes." 128

Moreover, after Brown \& Williamson, FDA has continued to rely on product design aspects as evidence of intended use outside of the tobacco context, in several circumstances. ${ }^{129}$ For example, in one warning letter, sent in 2000 to a company marketing a product called "Rejuvenique," the FDA argued that because the product was designed to "provide electrical current to the facial muscles to contract them," it was intended to affect the structure or function of the body — and was a device — "even if no claims were made for its specific use." 130 In 2003, FDA sent a warning letter to the a company marketing "Avacor Hair Care System," explaining that it was a drug intended for the treatment and prevention of hair loss and for the promotion of hair growth, because of "the claims made ... and the three individual products of which it is composed." 131 A final example is a 2010 warning letter was to the distributor of "Magic Power Coffee." In that warning letter, the agency asserted that the product was intended to prevent or treat disease or to affect the structure or function of the body in part because it contained an analogue of sildenafil, the active ingredient in Viagra, which the agency noted is "well known to

\footnotetext{
${ }^{123}$ See generally Brown \& Williamson, 529 U.S. 120 (U.S. 2000).

${ }^{124}$ Id.; see also Sottera 627 F.3d 891 (D.C. Cir. 2010).

${ }^{125}$ Cf. Grossman, supra note 88 at 1127 ("The Second Circuit acknowledged that the agency, in determining the "intended use" of a product, could look not only at labeling, promotional material, and advertising, but also to "any other relevant source.")

${ }^{126}$ Sudden Change at 742; see also Zettler, supra note 92 at $321 \mathrm{n} .18$ (discussing Sudden Change).

${ }^{127}$ Nat'l Nutritional Foods Ass'n v. Food \& Drug Admin., 504 F.2d 761, 789 (2d Cir. 1974).

${ }^{128} \mathrm{Id}$.

${ }^{129}$ See, e.g., 82 Fed. Reg. 2193, 2208 (Jan. 9, 2017) (providing examples of when the FDA has relied on product design as circumstantial evidence of intended use).

${ }^{130}$ Warning Letter from Larry D. Spears, FDA to Salton, Inc. (July 12, 2000)

http://www.casewatch.org/fdawarning/prod/2000/salton.shtml; see also Zettler, supra note 92 at $320 \mathrm{n} .13$

(discussing the same warning letter).

${ }^{131}$ Warning Letter to Global Vision Product (Apr. 3, 2003),

https://www.casewatch.org/fdawarning/prod/2003/globalvision.shtml.
} 
have an effect on the structure or function of the body." 132 To be clear, warning letters are not final agency action, nor are they general policy statements that provide the agency's official thinking or interpretation as a guidance document or regulation would. ${ }^{133}$ Agency interpretations set out in warning letters are not likely to receive deference from the courts. ${ }^{134}$ Nevertheless, these warning letters demonstrate that the agency has continued to take the position that a product's design, including its ingredients, can be evidence of intended use, and has done so for products other than those containing nicotine. Moreover, the FDA recently affirmed the position staked out in these Warning Letters in its January 2017 revisions to the definition of "intended use." 135

Each of the arguments about product design that the FDA made in its 1996 jurisdictional statement regarding tobacco products apply with equal force to synthetic nicotine products - and possibly with even more force given greater scientific knowledge about the effects of nicotine today. As was true in 1996, the biological effects of nicotine are widely known and accepted, and it is foreseeable to reasonable synthetic nicotine sellers that consumers will use the products for those effects. Sellers' disease and structure/function claims are evidence of this foreseeability — sellers anticipate that consumers will purchase their products for smoking cessation, harm reduction, or "biological impact," and seek to capitalize on that consumer interest through their marketing. ${ }^{136}$ Sellers also design their synthetic nicotine products to provide an effect on the bodies of consumers, as evidenced by the presence of nicotine in the formulations as well as by the fact different formulations have different strengths of nicotine. ${ }^{137}$ These different strengths might also be evidence of an intent for disease treatment- - for smoking cessation or nicotine addiction - because the different strengths, including the formulations with zero milligrams nicotine, may suggest the consumers can decrease their nicotine use gradually until they are using no nicotine at all. ${ }^{138}$ Finally, just as with tobacco products, nicotine in synthetic products is addictive, and can be expected to keep consumers using the product (including at least some consumers who intend to quit using, but are unsuccessful). Therefore, the design of synthetic nicotine products, and in particular the inclusion of nicotine as an

${ }^{132}$ Warning Letter from Ronald M. Pace, FDA to Peter Erlikh, INZ Distributors, Inc. (Aug. 23, 2010), https://wayback.archive-

it.org/7993/20170112004438/http:/www.fda.gov/ICECI/EnforcementActions/WarningLetters/ucm22543 2.htm; see also Zettler, supra note 92 at 320 (discussing the same warning letter).

${ }^{133}$ See Holistic Candlers \& Consumers Ass'n v. Food \& Drug Admin., 664 F.3d 940, 943 (D.C. Cir. 2012); FDA, Regulatory Procedures Manual § 4-1-1, https:/www.fda.gov/iceci/compliancemanuals/regulatoryproceduresmanual/ucm176870.htm\#SUB4-1.

${ }^{134}$ See, e.g., Sottera, Inc. v. Food \& Drug Admin., 627 F.3d 891, 899 (D.C. Cir. 2010) (Garland, J., concurring).

13582 Fed. Reg. 2193, 2208 (Jan. 9, 2017).

${ }^{136}$ See Section II.B.1, supra.

${ }^{137}$ See, e.g., NEXT GENERATION LABS, http://www.nextgenerationlabs.com/(last visited Aug. 31, 2017); cf. Margaret Gilhooley, Tobacco Unregulated: Why the FDA Failed, and What to Do Now, 111 YALE L.J. 1179,1183 (2002) (arguing that "the deliberate addition of an addictive substance would have made the case for seller intent much more straightforward" for tobacco products).

${ }^{138}$ Alternately, the no-nicotine formulations may be intended to be combined with flavorless formulations that contain nicotine. 
ingredient, alone may be sufficient evidence of intent to affect the structure or function of the body or to treat disease.

\section{Circumstances of Distribution}

In addition to sellers' representations about synthetic nicotine and the design of the products themselves, the "circumstances surrounding the distribution" of synthetic nicotine may be evidence that sellers intend these products to treat disease or affect the structure or function of the body. ${ }^{139}$ Specifically, consumer intent to use synthetic nicotine for its physiological effect may provide such evidence.

Courts have not often faced the question of whether consumer intent is relevant to determining the sellers' intent, likely because firms almost always make relevant claims about their products. When courts have addressed this issue, they have concluded that "evidence of consumer intent is a "relevant source" for determining intended use when "such evidence is strong enough to justify an inference as to the vendors' intent"-meaning that consumers use the product "predominantly and . . nearly exclusively with the appropriate intent." 140 In at least one case, U.S. v. Travia, a federal judge concluded that this standard was met. Travia involved the prosecution under the FDCA of several individuals who sold nitrous oxide ("laughing gas") in balloons outside a rock concert in Washington, D.C. ${ }^{141}$ Because the balloons were unlabeled and unadvertised, the government was not able to rely on the sellers' representations to demonstrate that nitrous oxide was a drug as defined in the FDCA. ${ }^{142}$ Nevertheless, Judge Thomas F. Hogan of the D.C. District Court agreed with the government's position that the nitrous oxide was a drug because "[1] abeling is not exclusive evidence of the sellers" intent," rather, intended use may be determined from any source. ${ }^{143}$ In the circumstances involved in Travia, "the environment provided the necessary information between buyer and seller"; the defendants, thus, did not need to label or advertise their product, and the government could demonstrate that the nitrous oxide was intended to affect the structure or function of the body. ${ }^{144}$ Furthermore, Congress has arguably approved of, or acquiesced to, this interpretation of consumer intent as relevant to the intended use inquiry by not amending the definition in the wake of Travia, or in the time since the FDA promulgated its regulation defining intended use broadly enough to encompass consumer intent; over 40 years ago. ${ }^{145}$

\footnotetext{
13921 CFR 201.128.

${ }^{140}$ Action on Smoking \& Health v. Harris, 655 F.2d 236, 239-40 (D.C. Cir. 1980); see also United States v. Travia, 180 F. Supp. 2d 115, 119 (D.D.C. 2001) (quoting the same language).

${ }^{141}$ Travia at 116-17. Nitrous oxide is not a controlled substance, which is likely why the government pursed the prosecution as a violation of the FDCA rather than the federal Controlled Substances Act, which is the more common avenue for prosecuting individuals selling recreational drugs. [Cite]

${ }^{142}$ Travia at 118-19.

${ }^{143}$ Id. at 119.

${ }^{144} I d$.

${ }^{145}$ See 41 Fed. Reg. 6911 (Feb. 13, 1976); Cf. Cortez, supra note 95 at 141 (discussing Congressional approval as one tool of statutory interpretation).
} 
Although Judge Hogan characterized the facts of Travia as "obviously unique," synthetic nicotine, likewise, presents an unusually compelling case for the relevance of consumer intent in determining intended use. In its 1996 jurisdictional statement regarding tobacco, the FDA described consumer intent as relevant to its determination that nicotine was a drug. The agency noted evidence that "consumers use [tobacco products' predominantly for pharmacological purposes," and "sellers of [tobacco products] know that nicotine in their products causes pharmacological effects ... and that consumers use their products primarily to obtain [these] effects." ${ }^{146}$ The agency went on to cite data finding that the vast majority of tobacco product users $(77-92 \%)$ were addicted to nicotine and used tobacco products to satisfy cravings, and that a majority also used tobacco for other pharmacological purposes, such as relaxation ( $70 \%$ of users aged 10-22 years old). ${ }^{147}$ Likewise, there is good evidence that consumers who use ecigarettes do so "predominantly" for their pharmacological effects, including their perceived smoking cessation benefits. Numerous surveys of adult e-cigarette users suggest that the most common reasons for e-cigarette use are to quit or reduce smoking and to reduce health risks. ${ }^{148}$ Youth are less likely to use e-cigarettes to quit smoking, and instead - according to the 2016 Surgeon General's Report — use e-cigarettes because of curiosity, flavorings/taste, and harm reduction compared to cigarettes. ${ }^{149}$ Harm reduction reflects consumer intent to use e-cigarettes for their physiological effects, specifically for disease prevention. Although consumer interest in e-cigarettes because of their flavorings or taste likely does not reflect consumer intent to achieve pharmacological effects, "curiosity" may reflect such intent, because teens may be curious about the physiological effects of nicotine, particularly in light of widespread media coverage and advertising campaigns alluding to these effects. ${ }^{150}$ Curiosity or experimentation, for example, is cited as a common reason for teens to initiate illicit drug use, a context in which curiosity almost certainly reflects an interest in experiencing the physiological effects of the product. ${ }^{151}$ Although the available research focuses on e-cigarettes generally, rather than synthetic nicotine specifically, there is little reason to think that synthetic nicotine consumers would have significantly different motivations.

The argument that consumer intent is relevant to the question of whether synthetic nicotine is a drug is likely the most controversial argument that we advance. As Lewis Grossman has explained, "[r]egulated industries contend that intended use is established solely by representations made in labeling, advertising, and other promotion. Conversely, the FDA

\footnotetext{
1461996 Jurisdictional Statement at 44630, https://www.gpo.gov/fdsys/pkg/FR-1996-08-28/pdf/X9620828.pdf Awareness, Use, Reactions and Beliefs: A Systematic Review, 23 TOBACCO CONTROL 275 (2014); J. Finney Rutten et al, Use of E-Cigarettes among Current Smokers: Associations Among Reasons for Use, Quit Intentions, and Current Tobacco Use, 17 PREV MED. 1228 (2016).

1492016 Surgeon General's Report, supra note 27, at 75.

${ }^{150}$ See, e.g., Jennifer C. Duke, et al., Exposure to Electronic Cigarette Television Advertisements Among Youth and Young Adults, 134 PEDIATRICS e29 (2014).

${ }^{151}$ National Institute on Drug Abuse, Principles of Adolescent Substance Use Disorder Treatment: A Research-Based Guide (2014), https://www.drugabuse.gov/publications/principles-adolescent-substanceuse-disorder-treatment-research-based-guide/frequently-asked-questions/why-do-adolescents-take-drugs.
} 
maintains that it can look to the overall circumstances of distribution, foreseeable use [and] actual use . . . to determine a product's intended use."152 Indeed, the extent to which the FDA can rely on a company's knowledge about how consumers use its product is currently at issue in the FDA's attempt to finalize revisions to its regulations defining intended use. ${ }^{153}$ Nevertheless, even with a narrow view of the circumstances in which consumer intent is relevant, there is a reasonable argument that synthetic nicotine presents one of the rare circumstances in which consumer intent is probative of sellers' intent.

The FDA, then, has three alternative ways of establishing intended use - sellers' representations about their products, the design of the products, and the circumstances of distribution - and all of which support the conclusion that the FDA can regulate synthetic nicotine as a drug. As suggested above, there may be stronger or weaker evidence with regard to the sellers' representations in any particular case, but the intentional decision to use nicotine and consumers' expectations with regard to the products will be constant across synthetic nicotine products (or at least those designed for use as e-liquids). In comparison to tobacco products (Brown \& Williamson) and e-cigarettes (Sottera), where the unique history of tobacco and the language of the TCA gave the courts pause, we believe the arguments for regulating synthetic nicotine as a drug are far more straightforward and compelling.

\section{The Policy CASe For Regulating Synthetic Nicotine AS A Drug}

Based on the evidence demonstrating that synthetic nicotine is generally intended to address disease or affect the structure or function of the body, there is a strong case that the FDA has the legal authority to regulate synthetic nicotine products as drugs. That FDA can regulate a particular product, however, does not mean that it will or that it should. Indeed, the FDA often exercises its discretion not to enforce requirements for a variety of reasons, and this may be particularly common for innovative products. ${ }^{154}$

In this section, therefore, we explore the question of whether FDA should regulate synthetic nicotine as a drug. We identify several reasons why regulating synthetic nicotine as a drug would be beneficial, and not unreasonably burdensome on industry. We conclude that, not only does FDA have the authority to regulate these products as drugs, it would serve FDA's public health mission - and the public - for it to do so, even when synthetic nicotine products are marketed without explicit smoking cessation claims.

\section{A. Treating Like Products Similarly}

\footnotetext{
${ }^{152}$ Grossman, supra note 88 at 1108 .

${ }^{153}$ See 82 Fed. Reg. 14319, 14320 (Mar. 20, 2017) (delay of effective date for final rule); Petition to Stay and for Reconsideration, https://www.regulations.gov/document?D=FDA-2015-N-2002-1977.

154 See, e.g., U.S. Food \& Drug Admin., Guidance: Mobile Medical Apps (2015), https://www.fda.gov/downloads/MedicalDevices/.../UCM263366.pdf; U.S. Food \& Drug Admin., Draft Guidance: Fecal Microbiota for Transplantation (2016), https:/www.fda.gov/downloads/biologicsbloodvaccines/guidancecomplianceregulatoryinformation/guida nces/vaccines/ucm488223.pdf; U.S. Food \& Drug Admin., Laboratory Developed Tests, https://www.fda.gov/MedicalDevices/ProductsandMedicalProcedures/InVitroDiagnostics/LaboratoryDev elopedTests/default.htm.
} 
It is a maxim in administrative law and theory that "like cases should be treated alike."155 Such consistency is viewed as fair, and indicative of an impartial, rational decision-making process that provides predictability for regulated entities. ${ }^{156}$ This notion of consistency is codified in the Administrative Procedure Act, which permits courts to set aside "arbitrary and capricious" agency decisions ${ }^{157}$ — the paradigmatic example of which is a decision that treats like cases differently. ${ }^{158}$

The FDA is not likely to judged "arbitrary and capricious" by a court for excluding synthetic nicotine products from its scheme for tobacco regulation, because the way the statute and the courts have defined tobacco products gives the FDA a legitimate reason for doing so. The FDA generally does not have the authority to regulate synthetic nicotine as a tobacco product, under the TCA, because the nicotine is not derived from tobacco, and the FDA does not have the authority to regulate tobacco-derived e-liquids (as "customarily marketed") as drugs under Sottera. Nevertheless, because there is no evidence that synthetic nicotine differs from tobacco-derived nicotine in its biological impacts on users, ${ }^{159}$ there is no scientific or public health rationale for treating the two categories of products differently. Additionally, allowing the subset of synthetically-derived e-liquids to evade regulation, while regulating tobacco-derived eliquids, may unfairly give synthetic nicotine products an advantage in the marketplace.

Regulating synthetic nicotine as a drug would allow the FDA to achieve the policy goal of treating all nicotine-containing e-cigarettes and e-liquids-regardless of whether they are tobacco-derived or not-more similarly than it otherwise could.

The FDA's schemes for regulating tobacco and drugs are distinct, but they parallel each other in important ways. As is true for drugs, tobacco products might be deemed misbranded if their labeling is false or misleading or fails to comply with FDA requirements, such as failing to disclose the seller or product ingredients, or failing to include relevant warnings. ${ }^{160}$ Similarly, both drugs and tobacco products might be deemed adulterated if they are contaminated, manufactured in insanitary conditions, or manufactured through methods that do not comply with good manufacturing practices. ${ }^{161}$ In short, both regulatory schemes are designed to ensure transparency, honesty, and safety.

Additionally, just as the FDA has a gatekeeping role for drugs, it now has such a role for tobacco products. "New tobacco products" - tobacco products "not commercially marketed as of February 15, 2007"-must be reviewed by the FDA before entering the market. ${ }^{162}$ The statutory standard for FDA approval of a tobacco product is the public health standard discussed in Part I, supra ("appropriate for the protection of the public health"), which includes

\footnotetext{
${ }^{155}$ Yoav Dotan, Making Consistency Consistent, 57 ADMIN. L. REV. 995, 999 (2005); see also Christopher J. Walker, How to Win the Deference Lottery, 91 TEX. L. REV. 73, 80 (2013) ("Consistency in agency interpretation should be given weight because it treats similarly situated parties the same, protects parties that rely on interpretations, and guards against arbitrary or capricious agency action.").

${ }^{156}$ See, e.g., Dotan, supra note 155 at 999.

1575 U.S.C. $\S 706(2)(\mathrm{A})$.

${ }^{158}$ See, e.g., Etelson v. Office of Pers. Mgmt., 684 F.2d 918, 926 (D.C. Cir. 1982); see also Bracco Diagnostics, Inc. v. Shalala, 963 F. Supp. 20, 27 (D.D.C. 1997) (the FDA “must treat similar cases in a similar manner unless it can provide a legitimate reason for failing to do so").

${ }^{159}$ See Danilo Delos Santos, NTN-A New Generation of Nicotine, HiLIQ (blog), Nov. 25, 2016, http://blog.hiliq.com/ntn-a-new-generation-of-nicotine.

16021 U.S.C. $\S \S 352,387 \mathrm{c}$.

16121 U.S.C. $\S \S 351,387 \mathrm{~b}$.

16221 U.S.C. $§ 387 j(a)$.
} 
consideration of "the risks and benefits to the population as a whole, including users and nonusers of tobacco products." 163 For drugs, the statutory standard is framed differently-for approval, a drug must be shown to be safe and effective for its intended uses. ${ }^{164}$ But the difference between the "safe and effective" standard for approval for drugs and the "appropriate for the protection of the public health" standard for tobacco products may not be as drastic as it seems at first glance. The FDA has long interpreted the "safe and effective" standard to mean that the benefits of a drug must outweigh its risks for it to be approved. In making that determination, the FDA, if appropriate, will consider the population health impacts of drugs, including their use in intended and unintended users. For example, the agency required a special risk mitigation program for certain high-dose opioid products in formulations likely to appeal to children, such as lozenges and lollipops, in part to prevent accidental exposure in children, who are not intended users of the product. ${ }^{165}$

As another example, in approving vaccines, FDA considers the benefits not only to the patient being inoculated against a particular disease, but also to others in the community who receive some benefit from the patient's protection. ${ }^{166}$ In other words, for appropriate drugssuch as synthetic nicotine - the FDA has the flexibility to consider population health factors in its regulatory decision-making similar to those it considers for tobacco products. ${ }^{167}$

Additionally, to the extent that synthetic nicotine products are being marketed as - or are widely understood by consumers to be - smoking cessation aids, they should be treated the same as NRTs and other smoking cessation products that the FDA already regulates as drugs. Otherwise, synthetic nicotine companies will be able to make unverified health claims, skirt quality control regulations, and take other actions that given them an unfair advantage in the marketplace (and potentially threaten public health).

\section{B. Protecting Consumers}

The classic rationale for FDA regulation, and its premarket review authority for drugs in particular, is that the agency protects consumers and the public health by preventing harmful products - unsafe or ineffective ones, or ones that do not have a net benefit for the public

16321 U.S.C. $\S 387 \mathrm{j}$.

16421 U.S.C. $\$ 355(\mathrm{~d})$.

${ }^{165}$ U.S. Food \& Drug Admin., Transmucosal Immediate Release Fentanyl (TIRF) Risk Evaluation and Mitigation Strategy (REMS) (2014), https://www.accessdata.fda.gov/drugsatfda_docs/rems/TIRF_201704-11_REMS_Document.pdf.

${ }^{166}$ See, e.g., Peter Lurie, Associate Commissioner, FDA, Integrating the Broader Public Health Consequences of Opioid Abuse and Misuse into the Evaluation of New Opioid Products (Nov. 4, 2016), http://www.nationalacademies.org/hmd/ /media/Files/Activity\%20Files/PublicHealth/PainResearch/LUR IE2.pdf.

${ }^{167}$ For these reasons, the drug review process is not likely to amount to a ban on synthetic nicotine, particularly if synthetic nicotine, and e-cigarette products in general, have the harm reduction benefits that advocates claim that they do. Along with the July 2017 announcement that the agency's tobacco policy would focus on nicotine, the FDA also announced that it is delaying the effective date of certain requirements of the deeming rule for products on the market in 2016, when the rule was issued. See FDA Nicotine Announcement, supra note 1. FDA regulation of currently marketed synthetic nicotine products, thus, could be similarly timed to parallel the implementation of requirements for currently marketing tobacco e-cigarette products. 
health - from entering the market. ${ }^{168}$ The need for this consumer protection arises because most drugs are "credence goods," meaning their safety, effectiveness, and quality cannot be readily and easily evaluated by patients and prescribers. ${ }^{169}$ This results in an information asymmetry. Prescribers and patients cannot access full information about the risks and benefits of a drug, and thus cannot make decisions that will force harmful or ineffective drugs from the marketplace. ${ }^{170}$ While other markets may have similar characteristics, the potentially serious consequences of taking harmful or ineffective drugs is cited to justify the FDA's role in this context. ${ }^{171}$

This rationale for the FDA's drug authorities applies to synthetic nicotine just as it applies to many "traditional" drugs. Consumers are not likely to be able to assess the veracity of sellers' claims related to smoking cessation, harm reduction, and the biological impact of synthetic nicotine, nor will consumers be able to determine which products may be more likely to pose risks or produce the benefits or biological effects that the consumer is seeking. Additionally, allowing synthetic nicotine products on the market without any FDA vetting may have negative, long-term consequences for consumers. For instance, unverified health claims may drive people towards using e-cigarettes with synthetic nicotine to quit smoking instead of using other therapies that may be more effective and pose fewer risks to cardiovascular and respiratory health.

More practically, the 2016 Deeming Rule lays out the public health case for applying the FDA's tobacco products authorities to e-cigarette, including tobacco-derived nicotine e-liquids. Because of the parallels between the regulatory regime for tobacco products and that for drugs, much of the same reasoning supports applying the FDA's drug authorities to synthetic nicotine. That is, regulating synthetic nicotine as a drug would serve the same consumer protection purposes that regulating other e-cigarette products under the scheme for tobacco products does.

One major public health concern is that e-cigarettes appeal, and are widely available, to adolescents and young adults, who are at an age of particular susceptibility to initiation of nicotine use and addiction. ${ }^{172}$ Adding to this concern, the FDA's research, conducted with the Centers for Disease Control (CDC), found an 800\% increase in e-cigarette use among high school students from 2011-2014, with e-cigarettes being the most commonly used tobacco product among that age group. ${ }^{173}$ Even though e-cigarettes are likely a less harmful way to use nicotine than smoking, nicotine use itself carries risks for user, and particularly minorsincluding interfering with neurological development, leading to long-term cognitive and mental health consequences. ${ }^{174}$ For e-cigarettes that are tobacco products, the FDA has several tools to address this public health issue, such as prohibiting the sale of e-cigarettes to minors, requiring certain warnings on product labeling, prohibiting characterizing flavors that attract youth users,

\footnotetext{
${ }^{168}$ See, e.g., Rebecca S. Eisenberg, The Role of the FDA in Innovation Policy, 13 MICH. TELECOMM. \& TECH. L. REV. 345, 348 (2007) (explaining "premarket approval is understood primarily as a consumer protection measure"); U.S. Food \& Drug Admin., History ("The Food and Drug Administration is the oldest comprehensive consumer protection agency in the U. S. federal government."), https://www.fda.gov/aboutFDA/WhatWeDo/History/.

${ }^{169}$ Ariel Katz, Pharmaceutical Lemons: Innovation and Regulation in the Drug Industry, $14 \mathrm{MICH}$. TELECOMM. \& TECH. L. REV. 1, 13 (2007).

${ }^{170} I d$.

${ }^{171} I d$.

${ }^{172}$ Deeming Rule, supra note 54, at 28981.

${ }^{173}$ Id. at 28984.

${ }^{174}$ See Section I.A., supra.
} 
and considering the potential impact on minors' use in the premarket review process. ${ }^{175}$ If synthetic nicotine is not regulated by the FDA, however, it may create an easy pathway for minors to access e-liquids and e-cigarettes that they otherwise would not have, thwarting the public health goals of the deeming rule. ${ }^{176}$ If, on the other hand, synthetic nicotine were regulated as a drug, the FDA could take steps to make e-cigarettes less accessible to minors to prevent minors' use. For example, if synthetic nicotine were sold over-the-counter without a prescription, the FDA could require that synthetic nicotine only be sold to adults over-the counter, similar to what the agency required for Plan B, the emergency contraceptive drug. ${ }^{177}$ As with tobacco products, the FDA could also require warnings on the labeling for synthetic nicotine and consider minors' use in its premarket review.

Regulation can also help ensure that e-cigarettes are not more harmful than necessary. For instance, the FDA is currently looking into the issue of e-cigarette battery safety. E-cigarette battery explosions have caused gruesome and severe injuries in some cases. ${ }^{178}$ Additionally, poor manufacturing practices could allow metals and other contaminants to enter e-cigarette aerosols, ${ }^{179}$ and some e-liquid flavors may include ingredients that are particularly toxic (e.g., diacetyl). ${ }^{180}$ The deeming rule envisions the FDA's premarket review of tobacco products as a means to protect consumers by preventing the sale of riskier products. Again, however, if synthetic nicotine products avoid any FDA regulation, this goal may be thwarted and consumers may have easy access to unreasonably risky products. If synthetic nicotine were regulated as a drug, however, the FDA could use its premarket review authority for drugs to address such concerns.

\section{Encouraging Research}

175 Tobacco Control Legal Consortium, The Deeming Regulation: FDA Authority over E-cigarettes, Cigars, and Other Tobacco Products (2017),

http://www.publichealthlawcenter.org/sites/default/files/resources/tclc-fda-deemingreg-regulationauthority-Dec2016.pdf.

${ }^{176}$ Although about 40 states now prohibit the sale of e-cigarettes to minors, many state laws may not apply to synthetic nicotine, depending how the definition of "tobacco product" is worded. See, e.g., Kristy Marynak et al., State Laws Prohibiting Sales to Minors and Indoor Use of Electronic Nicotine Delivery Systems - United States, Nov. 2014, 63 Morbidity \& Mortality Wkly. Rep. 1145, https://www.cdc.gov/mmwr/preview/mmwrhtml/mm6349a1.htm.

${ }^{177}$ Duramed Pharmaceuticals, Inc., Label for Plan B (levonorgestrel) Tablets (2009), https://www.accessdata.fda.gov/drugsatfda_docs/label/2009/021045s015lbl.pdf. Due to the political controversy associated with emergency contraceptives, the FDA's decision making with respect to minors' access to over-the-counter Plan B has a long, "bungled" history. Lisa Heinzerling, The FDA's Plan B Fiasco: Lessons for Administrative Law, 102 GEO. L.J. 927, 928 (2014). The only relevant point for the synthetic nicotine context, however, is that the FDA's drug authorities do give the agency some ability to limit minors' access to particular drug.

${ }^{178}$ E.g., Patty Pan, Exclusive: Man Severely Injured After E-Cigarette Blows Up in His Face, Fox5DC 8, September 2015. http://www.fox5dc.com/news/national/17391566-story.

${ }^{179}$ See, e.g., David Barboza, China's E-Cigarette Boom Lacks Oversight for Safety, N.Y. TIMES, Dec, 13, 2014.

${ }^{180}$ Jessica L. Barrington-Trimis et al., Flavorings in Electronic Cigarettes: An Unrecognized Respiratory Health Hazard?, 312 JAMA 2493 (2014). 
Although the FDA is often described as serving a consumer protection function, its premarket review authority also serves an important function in motivating research that produces the information necessary to assess the benefits and risks of products. ${ }^{181}$ Producing scientifically sound information about the effects of products is expensive and timeconsuming. ${ }^{182}$ Without a requirement that sellers demonstrate to the FDA that their drugs are safe and effective, or marketing their tobacco products is appropriate for the protection of the public health, companies are not likely to rigorously study the effects of their products. The dietary supplement industry provides a salient example. The claims that sellers make about dietary supplements, which are not subject to the FDA's premarket review, are rarely supported by rigorous scientific evidence. ${ }^{183}$

Using FDA oversight to motivate research into the effects of e-cigarettes is a particularly important public health goal. There is significant hope (and, perhaps, hype) about the potential for e-cigarettes use to reduce the harm associated with the use of traditional tobacco products, such as cigarettes (which are still the leading cause of preventable death in the United States). Although e-cigarettes seem to be less harmful than cigarettes, research, and particularly longterm studies, are needed to understand whether they provide a net benefit to the public health, what e-cigarette characteristics and marketing practices are likely to maximize public health benefits, and what unique harms (if any) may be associated with e-cigarette use. ${ }^{184}$ Indeed, the need to motivate research was one reason the FDA offered in support of its decision to promulgate the deeming rule. As the FDA explained, applying the agency's tobacco authorities to e-cigarettes "will provide FDA with critical information regarding the heath risks of the

${ }^{181}$ See, e.g., Eisenberg, supra note 168; see also U.S. FoOD \& DRUG ADMIN., MEMORANDUM: PUBLIC HEALTH INTERESTS AND FIRST AMENDMENT CONSIDERATIONS RELATED TO MANUFACTURER COMMUNICATIONS REGARDING UNAPPROVED USES OF APPROVED OR CLEARED MEDICAL PRODUCTS 6 (Jan. 2017), https://www.regulations.gov/document?D=FDA-2016-N-1149-0040 ("The FDA Authorities, among other things, motivate the development of scientific evidence that enables the reliable, populationlevel determination of the safety and efficacy of medical products for each intended use ..."), https://www.regulations.gov/document?D=FDA-2016-N-1149-0040; Christopher Robertson, When Truth Cannot Be Presumed: The Regulation of Drug Promotion Under an Expanding First Amendment, 94 B.U. L. Rev. 545, 561 (2014) ("[T]he FDCA does not exist to police the truth. Instead, the FDCA exists to provide and protect an epistemic and economic process of research and discovery ....").

${ }^{182}$ See, e.g., Rick Mullin, Cost to Develop New Pharmaceutical Drug Now Exceeds \$2.5 Billion, SCIENTIFIC AMERICAN, Nov. 24, 2014, https://www.scientificamerican.com/article/cost-to-develop-newpharmaceutical-drug-now-exceeds-2-5b/.

${ }^{183}$ See, e.g., Department of Health and Human Services Office of Inspector General (OIG), Dietary Supplements: Structure/Function Claims Fail To Meet Federal Requirements (2012), https://oig.hhs.gov/oei/reports/oei-01-11-00210.asp; see also Paul A. Offit, Do YOU BELIEVE IN MAGIC?: VITAMINS, SupPlEMENTS, AND All ThINGS NATURAL: A LOOK BEHIND THE CURTAIN (2013). Not only are the safety and effectiveness claims about dietary supplements often unsupported, a significant percentage of supplements have been found not to contain the dietary ingredients their labeling lists as ingredients, and supplements, particularly those marketed for sexual enhancement, weight loss, and athletic performance enhancement, are frequently tainted with active pharmaceutical ingredients. See, e.g., Steven G. Newmaster et al., DNA Barcoding Detects Contamination and Substitution in North American Herbal Products, 11 BMC MED. 222 (2013); U.S. Food \& Drug Admin., Tainted Products Marketed as Dietary Supplements, https://www.fda.gov/ForConsumers/ConsumerUpdates/ucm236774.htm.

${ }^{184}$ See, e.g. Deeming Rule, supra note 54 at 28984. 
products," which "is particularly important given the addictiveness of nicotine and the toxicity associated with tobacco products." 185

If, however, synthetic nicotine products are not subject to any FDA oversight, it is likely that synthetic nicotine will come to dominate the e-cigarette market. If the majority of ecigarettes fall outside FDA regulation, this result would be a lost opportunity to motivate industry to conduct rigorous research to answer the important questions about their products. But regulating synthetic nicotine as a drug would retain the information-producing benefits of FDA oversight - because sellers of synthetic nicotine would need to produce rigorous scientific evidence about their products to obtain FDA authorization for marketing.

\section{Promoting Innovation and Minimizing Burdens}

The suggestion that synthetic nicotine be regulated under the FDA's drug authorities is likely to produce objections that such regulation would stifle innovation in the industry or be unduly burdensome, perhaps even eliminating the burgeoning synthetic nicotine industry altogether. Indeed, these are common concerns about the FDA's decision to deem e-cigarette products subject to its tobacco authority, ${ }^{186}$ and the FDA's drug authorities are likely to be viewed as at least as onerous, if not more onerous, than its tobacco authorities. But contrary to these potential concerns, regulating synthetic nicotine as a drug may promote high-value innovation, ${ }^{187}$ and does not necessarily need to involve unreasonable burdens on sellers.

FDA oversight of drugs - and its premarket review authorities in particular — can be understood as motivating beneficial innovation, in that it requires sellers to produce products that do what sellers claim they will do. ${ }^{188}$ It serves, as one scholar has explained, as an "anti-lemon device." ${ }^{189}$ Regulating synthetic nicotine as a drug provides the opportunity for FDA to incentivize the development and sale of innovative synthetic nicotine products that deliver on industry's promise of a safe, or at least less harmful, way to use nicotine, just as the FDA can do for those e-cigarettes that are tobacco products.

Of course, even with these benefits, the FDA's drug authorities do impose burdens on regulated industry, including the often-long process of developing safety and effectiveness information for approval, as well as labeling, promotion, and manufacturing requirements. To the extent that e-cigarettes or e-liquids, including synthetic nicotine, hold real promise for reducing the harm associated with tobacco and nicotine use, unreasonable burdens on industry should concern industry and consumer advocate stakeholders alike. The key, then, may be finding a way to achieve the innovation benefits of regulating synthetic nicotine as a drug while assuring that the burdens are not unreasonable. Although we do not claim to identify the solution for achieving this balance, we note that there are several ways in which the FDA might

\footnotetext{
${ }^{185} \mathrm{Id}$.

${ }^{186}$ See, e.g., Michael B. Siegel, The FDA's Vaporous Thinking About E-Cigs, WALL ST. J., May 5, 2016, https://www.wsj.com/articles/the-fdas-vaporous-thinking-about-e-cigs-1462487690.

${ }^{187}$ See, e.g., Daniel Carpenter et al, Approval Regulation and Endogenous Consumer Confidence: Theory and Analogies to Licensing, Safety, and Financial Regulation, 4 REG. \& GOVERNANCE 383 (2010).

${ }^{188}$ See id.; Katz, supra note 169; see also Nathan G. Cortez, et al, FDA Regulation of Mobile Health Technologies, 371 NEW ENG. J. MED. 372, 376 (204) ("The true challenge, however, is creating a regulatory framework that encourages high-value innovation while also preventing the market from being overcome with products that are ineffective or unsafe").

${ }^{189}$ Katz, supra note 169 , at 17.
} 
streamline the process to market for synthetic nicotine while preserving the benefits of regulating synthetic nicotine as a drug.

One option might be for the FDA to exercise its discretion not to enforce certain drug requirements applicable to synthetic nicotine. Exercising enforcement discretion is a tool that the agency has used to tailor its regulatory scheme for a number of other innovative technologies, including mobile medical apps, fecal microbiota transplantation, and certain genetic tests. ${ }^{190}$ Similarly, for synthetic nicotine, if the scientific evidence supported such an approach, the FDA might decide not to enforce premarket review requirements for products that were not marketed as smoking cessation aids and were substantially equivalent to legally marketed tobacco products (with the only difference being synthetic nicotine in place of tobacco-derived nicotine). Such an approach would enable synthetic nicotine products to reach the market in a manner similar to that of e-cigarettes regulated as tobacco products.

As Eric Lindblom has suggested for e-cigarettes subject to the FDA's tobacco-related jurisdiction, another option would be to promise expedited premarket review (and presumptive approval) to companies that agreed to take actions likely to reduce potential negative public health consequences associated with e-cigarette use. ${ }^{191}$ For example, companies could agree to market their products only to adults who are currently smokers, to include labeling or warnings explaining the dangers of dual use, and to conduct certain types of postmarket surveillance. Although this approach may raise concerns about the FDA's ability to enforce such industry commitments, ${ }^{192}$ it may be an appropriate option if the hope that e-cigarettes, including synthetic nicotine products, will provide significant public health benefits is demonstrated.

Finally, particularly because it seems likely that synthetic nicotine would be marketed as an over-the-counter (OTC) drug, rather than one requiring a prescription, the FDA also might have options for allowing the marketing of synthetic nicotine products without requiring a product-by-product review. ${ }^{193}$ The vast majority of OTC drugs are marketed pursuant to an "OTC Monograph"- a regulation promulgated by the FDA that establishes the conditions under which the FDA will consider a drug to be generally recognized as safe and effective, and not misbranded, such that it can be marketed without premarket approval. ${ }^{194}$ Although the OTC

${ }^{190}$ U.S. Food \& Drug Admin., Guidance: Mobile Medical Apps (2015), https://www.fda.gov/downloads/MedicalDevices/.../UCM263366.pdf; U.S. Food \& Drug Admin., Draft Guidance: Fecal Microbiota for Transplantation (2016), https://www.fda.gov/downloads/biologicsbloodvaccines/guidancecomplianceregulatoryinformation/guida nces/vaccines/ucm488223.pdf; U.S. Food \& Drug Admin., Laboratory Developed Tests, https://www.fda.gov/MedicalDevices/ProductsandMedicalProcedures/InVitroDiagnostics/LaboratoryDev elopedTests/default.htm.

${ }^{191}$ Eric N. Lindblom, Effectively Regulating E-Cigarettes and Their Advertising-and the First Amendment, 70 FoOD \& DRUG L.J. 55, 75-76 (2015).

192 The FDA, historically, has faced challenges enforcing premarket commitments made by pharmaceutical companies. See, e.g., Kevin Fain et al., The Food and Drug Administration Amendments Act and Postmarketing Commitments, 310 JAMA 202, 202-03 (2013); U.S. DEP'T HEALTH AND HUMAN SERVS, OEI-04-11-00510, OFFICE OF INSPECTOR GENERAL, FDA LACKS COMPREHENSIVE DATA TO DETERMINE WHETHER RISK EVALUATION AND MITIGATION STRATEGIES IMPROVE DRUG SAFETY, at 1422 (Feb. 2013), https://oig.hhs.gov/oei/reports/oei-04-11-00510.pdf.

19321 U.S.C. $\S 353($ b)(1). Currently marketed drugs that contain nicotine, such as gums, lozenges, and transdermal patches intended as smoking cessation aids, are marketed over-the-counter.

${ }^{194}$ See, e.g., U.S. Food \& Drug Admin, Over-The-Counter Drug Monograph System-Past, Present, and Future; Public Hearing, 79 Fed. Reg. 10169 (Feb. 24, 2014). 
Monographs are generally available only to drugs that were marketed when the FDA began its systematic review of OTC drugs in 1972, there is a mechanism for adding later-introduced drugs to the monograph process. ${ }^{195}$ Through this mechanism, it might be possible to add synthetic nicotine to OTC monograph, once more data is available on the conditions under which synthetic nicotine products are safe and effective.

This list does not exhaust the options that the FDA may have for reducing the burdens of regulation on synthetic nicotine sellers, and determining what approaches may be appropriate deserves more detailed consideration. But these examples do show that claims that FDA regulation necessarily will unreasonably burden the synthetic nicotine industry are not persuasive. Moreover, although all burdens associated with FDA regulating synthetic nicotine as a drug cannot be eliminated, importantly those burdens may have numerous benefits, including enabling the agency to treat like products similarly, protecting consumers, incentivizing rigorous studies of synthetic nicotine, and encouraging beneficial innovation in this space.

\section{CONCLUSION}

The current regulatory gap for synthetic nicotine-wherein tobacco-derived nicotine is subject to FDA regulation and synthetic nicotine is not - may prompt more and more companies to "mak[e] business choices on the basis of the difference between the two regulatory domains." 196 Such "regulatory arbitrage" serves no public health purpose and threatens to undermine the FDA's newly announced "comprehensive plan for nicotine and tobacco regulation." 197 There is, however, a fix available: the FDA can regulate synthetic nicotine products as drugs. This solution is not perfect; ideally, all nicotine-containing products (or at least all nicotine-containing e-liquids) would be subject to the same regulatory scheme, regardless of the source of the nicotine. But, as demonstrated in this Article, this approach is legally sound and promotes the public's interests in sound regulation and consumer protection without sacrificing innovation. The FDA is poised to begin a promising new phase of tobacco and nicotine regulation; synthetic nicotine, if properly regulated as a drug, could play a key role in the FDA's effort to transition current smokers to less harmful nicotine products.

\footnotetext{
${ }^{195}$ See U.S. Food \& Drug Admin, Guidance for Industry: Time and Extent Applications for Nonprescription Drug Products (Sept. 2011), https://www.fda.gov/downloads/drugs/guidances/ucm078902.pdf.

${ }^{196}$ Nicolas P. Terry, Regulatory Disruption and Arbitrage in Health-Care Data Protection, 17 YALE J. HEALTH POL'Y, L. \& ETHICS 143, 156 (2017).

${ }^{197}$ FDA Nicotine Announcement, supra note 1.
} 